\title{
CONFIDENCE dissemination meeting: Summary on the scenario-based workshop
}

T. Duranova ${ }^{1, *}$, P. Bedwell ${ }^{2}$, N.A. Beresford ${ }^{3}$, M. Bleher ${ }^{4}$, F. Gering ${ }^{4}$, G. Geertsema ${ }^{5}$, T. Hamburger ${ }^{4}$, J.C. Kaiser ${ }^{6}$, I. Korsakissok ${ }^{7}$, S.J. Leadbetter ${ }^{8}$, M. Montero ${ }^{9}$, T. Müller ${ }^{10}$, D. Oughton ${ }^{11}$, T. Perko ${ }^{12}$, W. Raskob ${ }^{10}$, J. Tomas ${ }^{13}$, C. Turcanu ${ }^{12}$, H. de Vries ${ }^{5}$, L. Walsh ${ }^{14}$ and C. Woda ${ }^{6}$

1 VUJE - VUJE, a.s., Trnava, Slovak Republic.

${ }^{2}$ PHE - Public Health England, Centre for Radiation, Chemical and Environmental Hazards, Didcot, UK.

${ }^{3}$ CEH - UK Centre for Ecology \& Hydrology, Lancaster, UK.

${ }^{4}$ BfS - Federal Office for Radiation Protection, Neuherberg, Germany.

${ }^{5}$ KNMI - Royal Netherlands Meteorological Institute, Utrechtseweg, The Netherlands.

${ }^{6}$ HMGU - Helmholtz Zentrum München-German Research Center for Environmental Health, Neuherberg, Germany.

${ }^{7}$ IRSN - Institute for Radioprotection and Nuclear Safety, Fontenay-aux-Roses, France.

${ }^{8}$ Met Office, Exeter, UK.

9 CIEMAT - Centro de Investigaciones Energéticas, Medioambientales y Tecnológicas, Madrid, Spain.

${ }^{10}$ KIT - Karlsruhe Institute of Technology, Eggenstein-Leopoldshafen, Germany.

${ }^{11}$ NMBU/CERAD - Norwegian University of Life Sciences, Centre for Environmental Radioactivity, Ås, Norway.

12 SCK-CEN - Belgian Nuclear Research Centre, Mol, Belgium.

13 RIVM - National Institute for Public Health and the Environment, Bilthoven, The Netherlands.

${ }^{14}$ UZ - University of Zürich, Department of Physics, Science Faculty, Zürich, Switzerland.

\begin{abstract}
The CONFIDENCE dissemination workshop "Coping with uncertainties for improved modelling and decision making in nuclear emergencies" was held in December 2-5, 2019 (Bratislava, Slovak Republic). About 90 scientists and decision makers attended the workshop. The dissemination workshop allowed the presentation of the CONFIDENCE project results, demonstration of the applicability of the developed methods and tools in interactive discussion sessions and the collection of feedback from the participants. The results were disseminated not only in the form of presentations and posters but also through interactive workshops where all participants were involved in round table working groups. A fictive accidental release scenario taking place at a nuclear power plant was developed and used by each work package in the workshop to provide the basis for interactive sessions and discussions.
\end{abstract}

Keywords: dissemination of results / interactive scenario-based workshop / uncertainties / decision support / CONFIDENCE

\section{Introduction}

The CONFIDENCE Project, funded under the H2020 EJP CONCERT (European Joined Project), performed research focused on uncertainties in the area of emergency management and long-term rehabilitation. It concentrated on the early and transition phases of an emergency, but also considered longerterm decisions made during these phases. The project brought together expertise from four European Radiation Protection Research Platforms (NERIS, MELODI, ALLIANCE and EURADOS) and also from SHARE (Social Sciences and

\footnotetext{
* Corresponding author: tatiana.duranova@vuje.sk
}

Humanities network). The CONFIDENCE Final Dissemination workshop "Coping with uncertainties for improved modelling and decision making in nuclear emergencies" was held in December 2019 (Bratislava, Slovak Republic). About 90 scientists and decision makers attended the workshop.

The objectives of this final workshop were as follows:

- to disseminate the knowledge acquired and to demonstrate the capability of the developed models, methods, approaches, guidance, recommendations and tools;

- to collect feedback from end users on outputs and remaining research requirements, or improvements, in models or guides; this feedback may be used by the Radiation Protection Research Platforms to further develop their Strategic Research Agendas and Joint roadmap. 


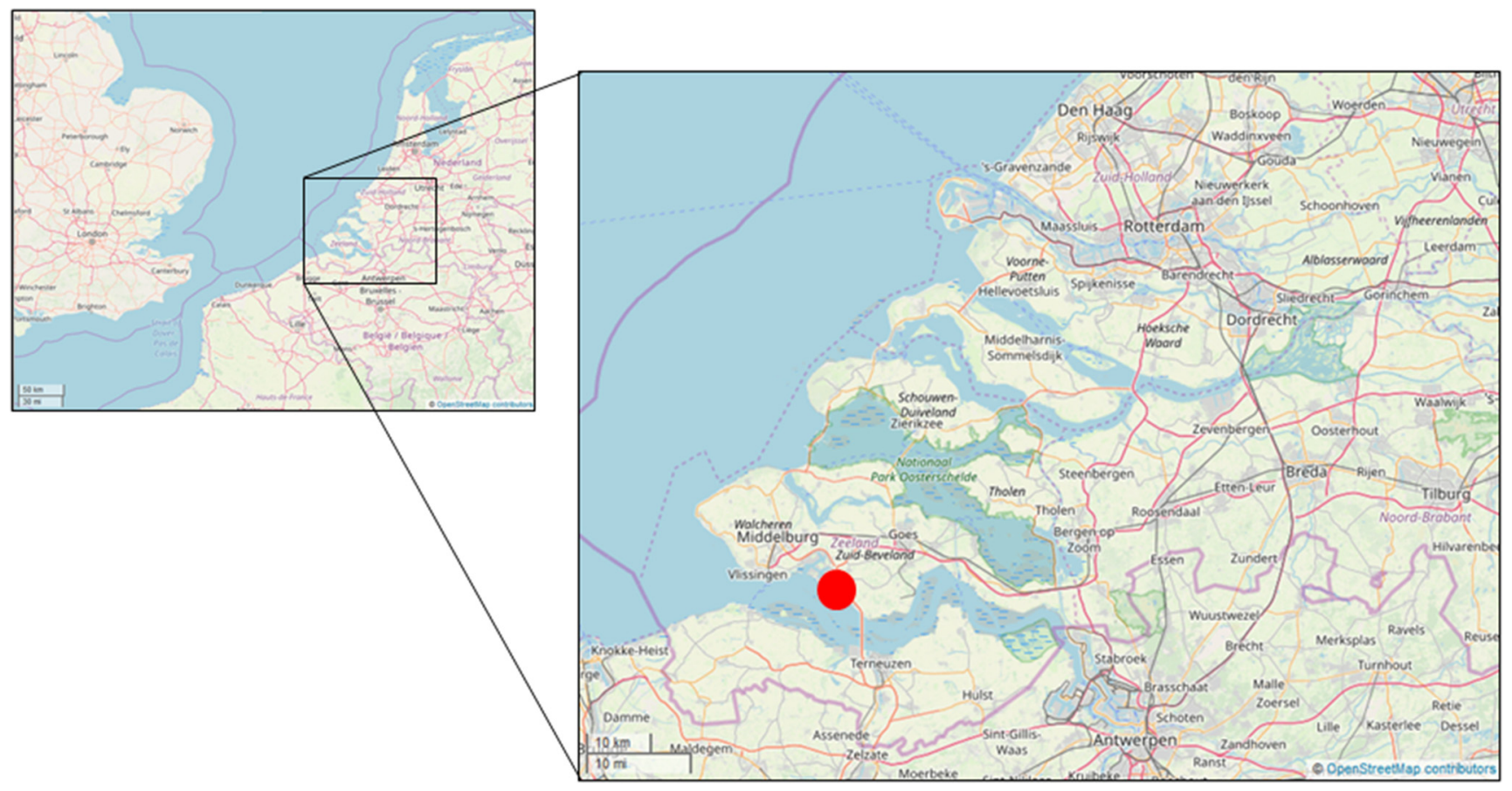

Fig. 1. Location of the hypothetical scenario.

The workshop was designed to be of value to the different actors in emergency and recovery preparedness and management: decision makers, advisors, researchers and stakeholders (professional and students including early career researchers) at various levels (international, national, regional, local) that may play a role within the decision making process during the post-release and transition phases of a nuclear/radiological accident.

The complexity of the areas of research as well as a variety of tools and methods developed under the CONFIDENCE project provided an opportunity to perform the dissemination of the results in an interactive way. The workshop comprised presentations, panels, poster sessions and scenario-based facilitated group discussions. Each work package (WP) of the CONFIDENCE project dealt with different stages of the decision making process. The WP used various tools and methods, including simulation, measurements, surveys and panels. The workshop program alternated between WP presentations and interactive discussions using the same scenario as a common thread (described in Sect. 2), but oriented toward issues and outputs specific to each WP (presented in Sect. 3). The programme followed the stages of a decision making process in case of an accidental release of radioactive material.

\section{Using a scenario as a key method of communication CONFIDENCE outputs}

To facilitate the workshop a scenario-based on a (fictitious) large nuclear accident at the Borssele power plant in the Netherlands (Fig. 1) was developed; extensive territories in this country and in the neighbouring Belgium were affected by the resultant plume. It was based on the hypothetical accident scenario used by WP1 for uncertainty propagation, the so-called

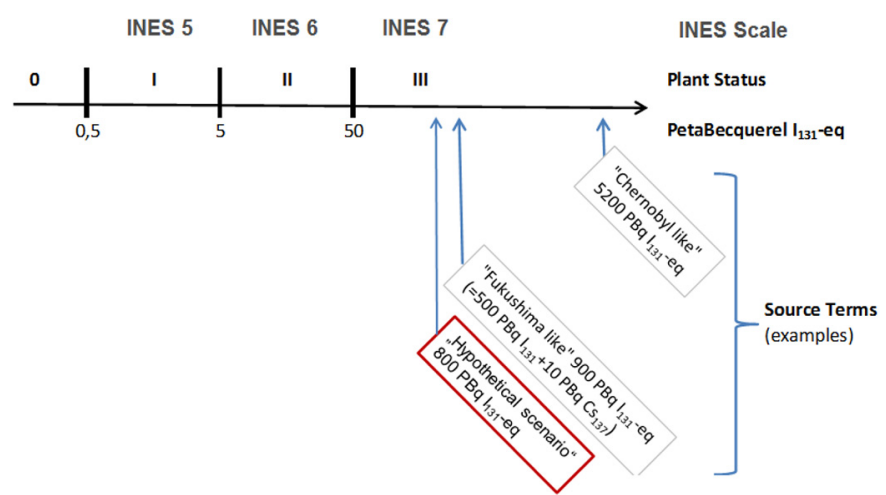

Fig. 2. Source term of the hypothetical scenario and its position on the INES scale (International Nuclear and Radiological Event Scale) compared to the Chernobyl and Fukushima accidents.

Radiological Ensemble Modelling (REM) case study, with the short release scenario (Korsakissok et al., 2020).

All presentations and the facilitated discussions and group work used the scenario as a common thread, demonstrating CONFIDENCEs outputs and prompting discussion.

\subsection{Release scenario}

The source term originally designed and used by WP1 for the REM case study was scaled to a 900 MWe reactor (instead of $485 \mathrm{MWe}$ at Borssele). For the purpose of demonstration, the source term was artificially multiplied by a further factor of 5 in order to have large consequences, for instance in terms of population or surface above a given dose threshold. This increase led to an accidental release of $800 \mathrm{PBq} \mathrm{I}-131$ equivalent, comparable to the Fukushima release (Fig. 2).The radionuclides 


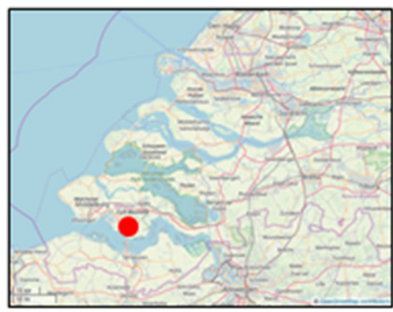

\section{$T_{0}$ of the ensemble forecast $=11$ July 2017 06:00 UTC (original data from January)}

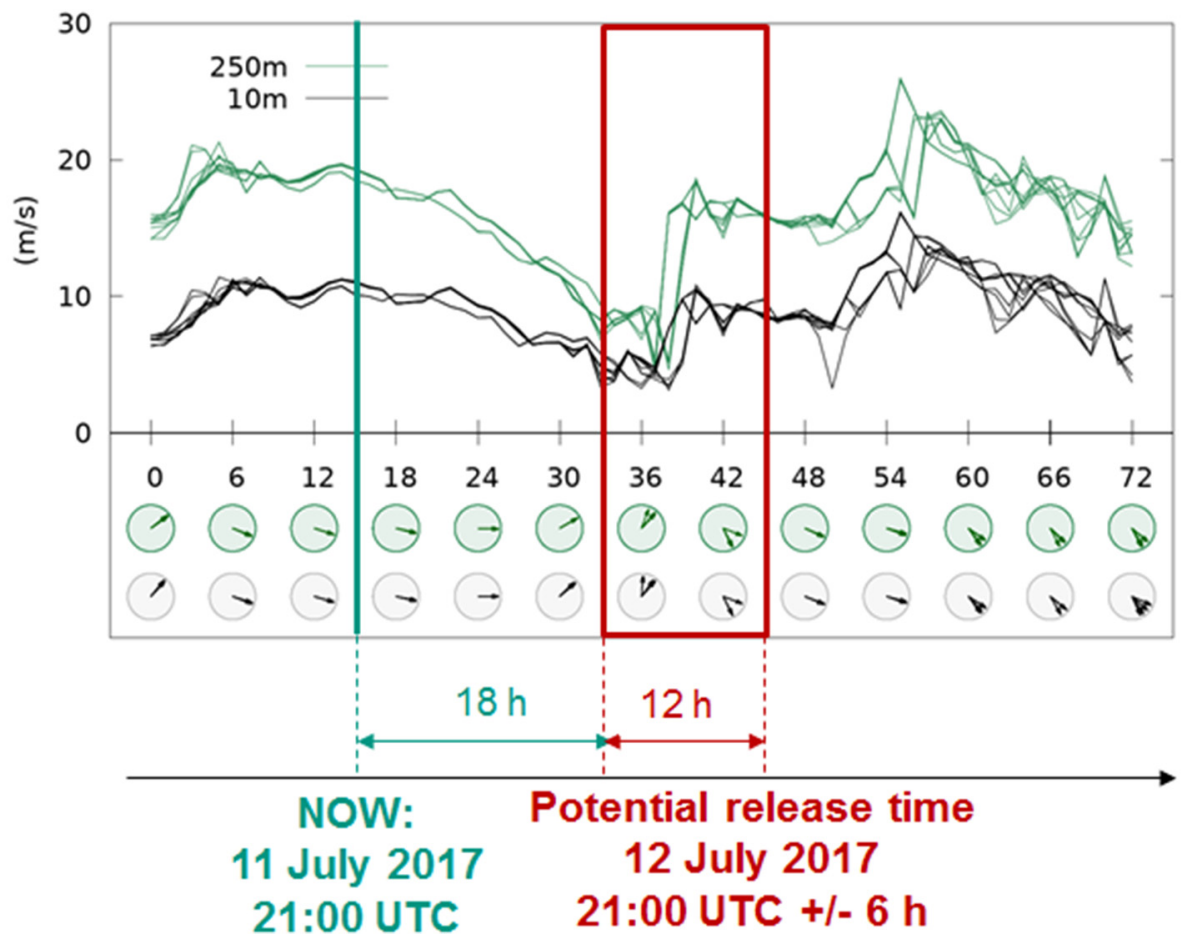

Fig. 3. Wind speed and direction at the source location, forecast by the ensemble members at $10 \mathrm{~m}$ (black) and $250 \mathrm{~m}$ (gray) above ground. The $\mathrm{x}$-axis shows the number of hours after beginning of meteorological forecast, "Now" is the time when the decision making takes place during the first stage. The "potential release time" is at 21:00 UTC \pm 6 hours (dark rectangle).

considered were: ${ }^{90} \mathrm{Sr},{ }^{131} \mathrm{I},{ }^{132} \mathrm{I},{ }^{132} \mathrm{Te},{ }^{133} \mathrm{Xe},{ }^{137 \mathrm{~m}} \mathrm{Ba},{ }^{134} \mathrm{Cs}$, ${ }^{136} \mathrm{Cs}$ and ${ }^{137} \mathrm{Cs}$. The release duration was four hours. Uncertainties on the release time were considered to be \pm 6 hours.

\subsection{Meteorological scenario}

The meteorological fields were provided by KNMI using the high-resolution HARMONIE-AROME model. An ensemble of 10 meteorological members was constructed by KNMI to represent the meteorological uncertainties (Geertsema et al., 2019). The meteorological scenario (corresponding to WP1 case study REM-2) featured a meteorological variability in the wind direction and precipitation within a few hours during the passage of a warm front (Figs. 3 and 4).

The content of the meteorological fields was "shifted" in time from January to July in order to have a significant impact on food products such as milk (with cows grazing outside in July), cereals or vegetables (Hamburger et al., 2020). This enabled the consideration of agricultural countermeasures.

\subsection{Combination of uncertainties in wind direction, precipitation and release time}

The uncertainty associated with the release time was \pm 6 hours, and the potential release period covered the time during which the warm front passage occurred, leading to significant variability in wind speed and direction (Fig. 3).

The wind direction change and precipitation, combined with the uncertainty in the release time, led to large differences in the plume trajectory and subsequent footprint (Fig. 4). The plume travelled northeast when considering a release at 12:00 UTC on day D (12/07/2017 in the interactive scenario) with small to medium amounts of precipitation, whilst it was advected south-southeast if the release occurred later (at 18:00 UTC on day D or 00:00 UTC on day D +1 ), with heavy precipitation around 18:00 UTC. This induced large uncertainties in the health consequences and subsequent countermeasures to be taken, which were tackled in the WP1 part of the interactive discussion (Sect. 3.1).

During the workshop, each WP introduced other types of uncertainties related to their specific research and developments, in order to demonstrate the outcomes and facilitate discussions and feedback from the workshop participants.

\section{Summary of scenario-based demonstrations and feedback}

The following sections provide information on the way each CONFIDENCE WP adapted the scenario to their specific issues, and summarises the resulting discussions and feedback from the participants. 


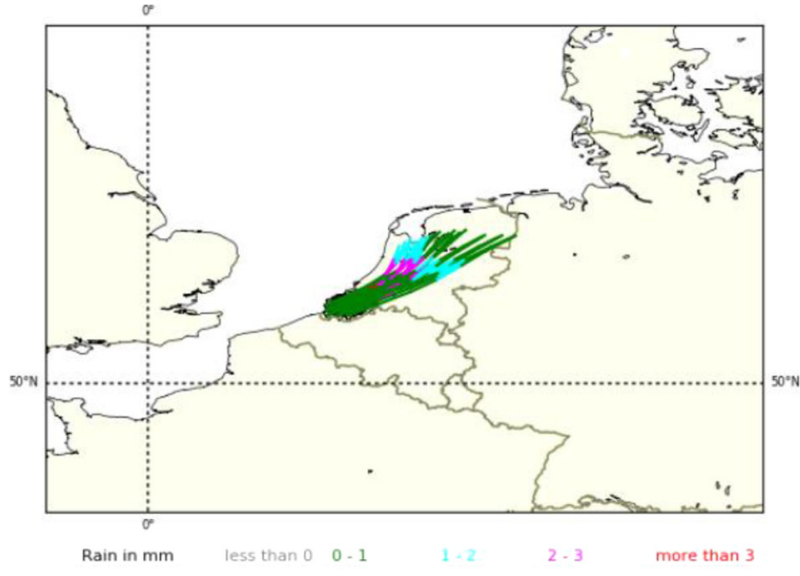

(a) Release at 12:00 UTC

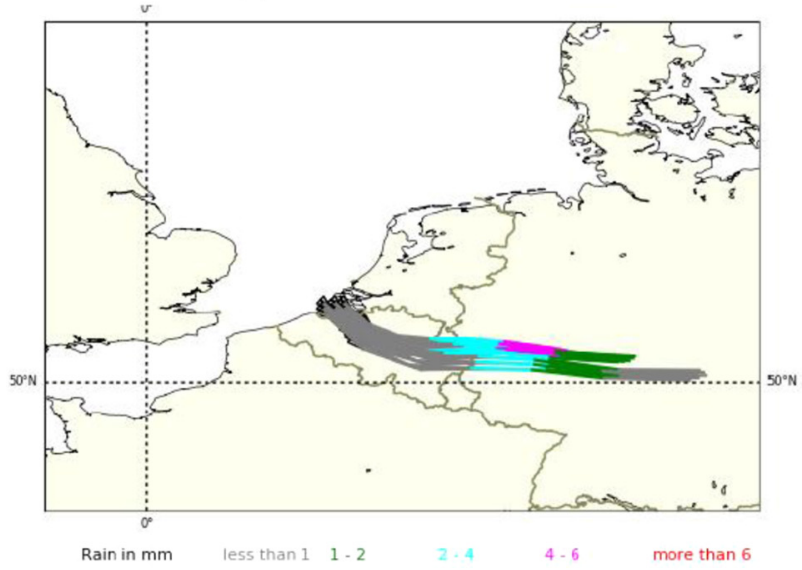

(c) Release at 00:00 UTC on day+1

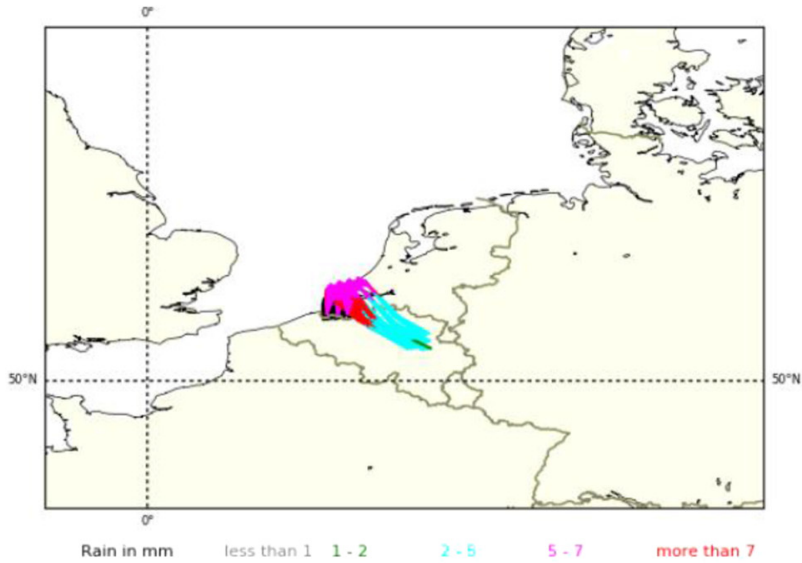

(b) Release at 18:00 UTC

Fig. 4. Indicative 6-hour plume trajectories based on analysed weather as a function of height (between $10 \mathrm{~m}$ and $500 \mathrm{~m}$ ), for a release on $12 / 07 /$ 17 at 12:00, 18:00 UTC, and 13/07/17 at 00:00 UTC and rain (cumulated in one hour). Trajectories plotted by KNMI.

\subsection{Model improvement in the pre- and release phase, through uncertainty analysis and propagation with an ensemble approach (WP1)}

The issues tackled during the interactive discussions led by WP1 were related to the emergency phase. Specifically, the audience was asked to play the role of decision makers in an emergency situation, where decisions have to be made for the protection of the population before the release occurs. The discussion was divided in two stages. In the first stage (stage 1), the audience was advised that possible release was anticipated to take place within 24 hours, with an uncertainty of \pm 6 hours (Figs. 3 and 5). The second stage (stage 2), 12 hours before the release, updated the scenario with new information on the accidental situation: the release time was now certain (Fig. 9). In the first stage, discussions focused on evacuation and sheltering. During the second stage, decisions made in the first stage were reviewed in light of the updated situation.

The goal of this exercise was to consider how uncertainties intrinsic to an emergency situation could be dealt with during the decision making process. In particular, several maps were presented to the audience in order to present as clearly as possible the different options. One of the feedbacks requested from the participants concerned the maps and outputs that were useful for decision making (Fig. 6).
Background information - stage 1

\section{Estimated time to release: 24 hours}

- There is an accident on the Borssele NPP. Experts have produced an estimation of the potential release that may occur within the next $24 \mathrm{~h}$, with an uncertainty on the release time and meteorology (wind direction change is forecast).

- Estimated release date and time: 12 July 2017 21:00 UTC (23:00 local time)

- Uncertainty of release time: $-6 h,-3 h, 0 h,+3 h,+6 h(5$ release times considered $)] 50$

- Uncertainty of meteorological data: 10 members considered Jsimulations

- Decision has to be made now (or soon) to protect the population

- Presentation of several maps / support followed by 10-minutes discussion

- Focus on:

- Evacuation

- Sheltering
- Food restriction

Maps and other information provided for discussion

Frequency (" probability ") maps: give an information on which area as the highest " risk » of threshold exceedance, according to our ensemble

- Sheltering: effective dose above $10 \mathrm{mSv}$ Prognosis of 48 hours since the start of the

- Evacuation: effective dose above $100 \mathrm{mSv}$ release (Responsplan, the Netherlands)

Maps of effective dose for particular realizations

Population within the area of threshold exceedance

Fig. 5. Stage 1 of WP1 discussions. Estimated time to release -24 hours. Uncertainty in the release time: \pm 6 hours.

- What would be your recommendations to decision makers?

- In which areas implement evacuation / sheltering?

- On the basis of which map / variable / criteria?

- What additional information would you need?

- What supports are useful / confusing / needed by experts / decision makers?

Fig. 6. Questions asked to the audience during stage 1 of WP1 discussions. 


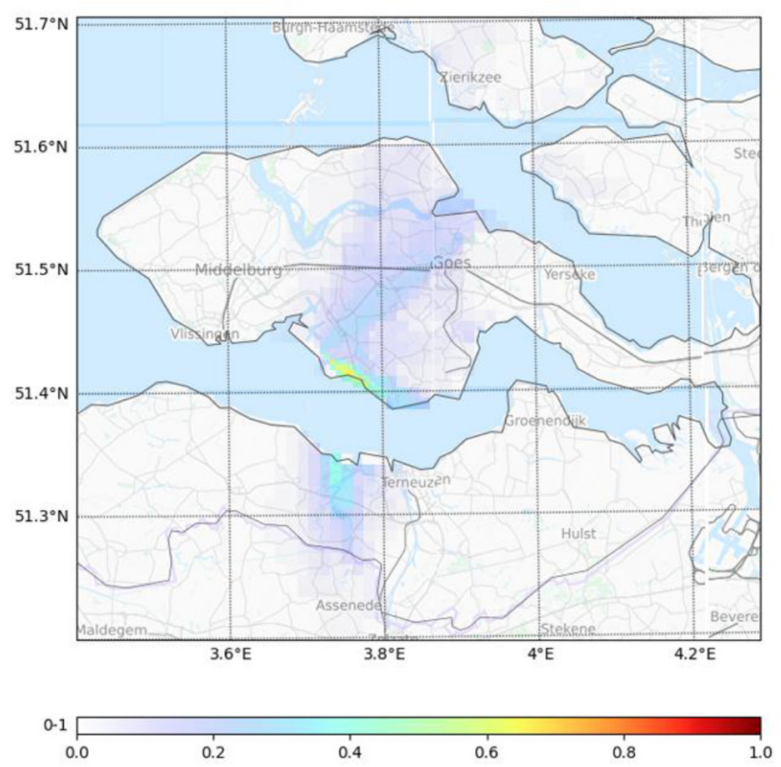

(a) threshold exceedance of $100 \mathrm{mSv}$ of effective dose

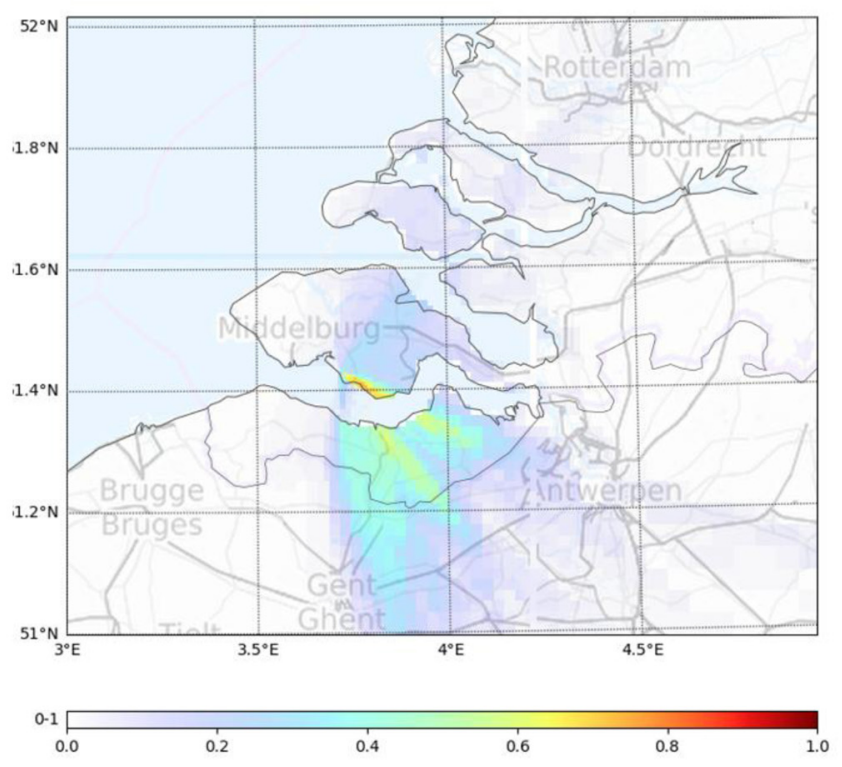

(b) threshold exceedance of $10 \mathrm{mSv}$ of effective dose

Fig. 7. Prognostic frequency map for areas above the threshold value for evacuation (left) and sheltering (right), considering an uncertainty in the release time of \pm 6 hours. The value 0 corresponds to areas where no simulation forecast a threshold exceedance, and 1 (red (black in B\&W printed version)) implies that all simulations considered predict a value above the threshold.

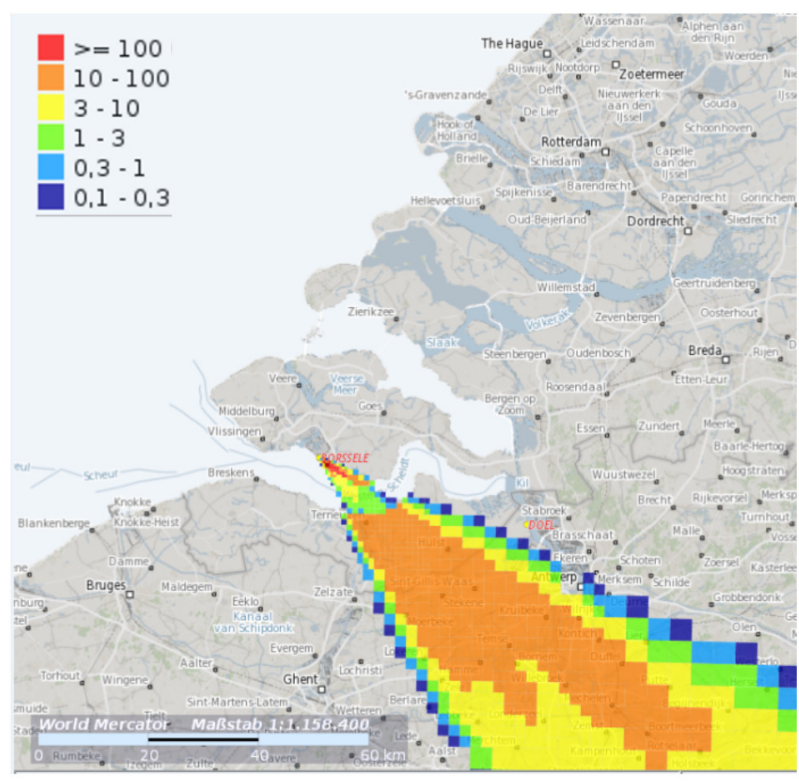

(a) Least severe scenario in terms of population (member 29)

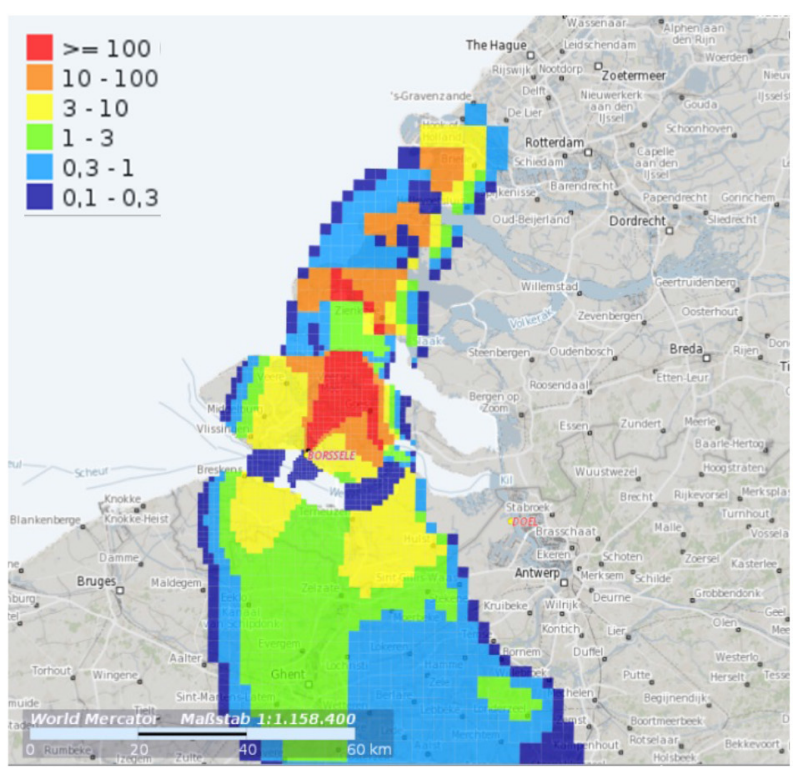

(b) Worst case scenario in terms of population (member 41)

Fig. 8. Maps of effective dose for (a) the "least severe" and (b) the "worst case" scenarios in terms of population affected by the threshold exceedance. The first item in the legend (red colour) corresponds to evacuation and the second item in legend (orange colour) to sheltering criterion.

For both stages, background information and maps were presented to the audience, which was then divided into groups of about 10 people. In stage 1 , half of the groups discussed evacuation and the others, sheltering. In stage 2, all groups were to review their decisions taken in the first stage and to discuss food ban. Each round of discussion took 15 minutes, followed by 15 minutes of feedback (each group had to nominate a referee to report the discussions and decisions reached).

\subsubsection{WP1 scenario-based discussions: stage 1 \\ 3.1.1.1 Presentation of the support for discussion}

The discussions within the stage 1 focused on sheltering and evacuation of the population and were driven by the questions given in Figure 6.

To inform discussion, several maps were presented to the audience. For a given dose corresponding to a particular 


\section{Background information - stage 2 Estimated time to release: 12 hours}

There is an accident on the Borssele NPP. Experts have produced an estimation of the potential release that may occur within the next $12 \mathrm{~h}$, with an uncertainty on the release time and meteorology (wind direction change is forecast).

- Estimated release date and time: 12 July 2017 15:00 UTC (17:00 local time)

- No uncertainty on release time

- Uncertainty of meteorological data: 10 members considered (no change)

- Decision has to be made now to protect the population

- Presentation of several maps / support followed by 10-minutes discussion

- Focus on:

- Evacuation

- Sheltering

- Food restriction

Additional information for food restriction discussion:

- Deposition maps of ${ }^{137} \mathrm{Cs}$ and ${ }^{131}$, surface covered by threshold exceedance

- Levels used in post-accidental phase, for commercialization:

- Leafy vegetables: $1250 \mathrm{~Bq} / \mathrm{kg}^{137} \mathrm{Cs}, 2000 \mathrm{~Bq} / \mathrm{kg}^{131}$

- Milk: $1000 \mathrm{~Bq} / \mathrm{kg}{ }^{137} \mathrm{Cs}, 500 \mathrm{~Bq} / \mathrm{kg}{ }^{131} \mathrm{l}$

- Grazing ban: ground contamination, $5000 \mathrm{~Bq} / \mathrm{m}^{2}{ }^{131}$

Fig. 9. Stage 2 of WP1 discussions. Estimated time to release 12 hours. No uncertainty in the release time.
- Considering the decisions taken before, is the evacuation / sheltering sufficient with respect to the new information?

- What complementary decisions could you recommend?

- On the basis of which map / variable / criteria?

- What additional information would you need?

- What supports are useful / confusing / needed by experts / decision makers?

Fig. 10. Questions for WP1 discussion for stage 2-evacuation and sheltering.

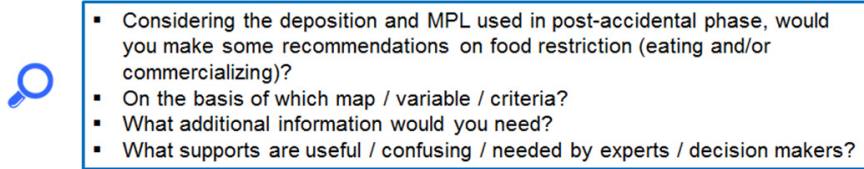

Fig. 11. Questions for WP1 discussion for the stage 2-food restriction.

\section{Uncertainties on release time $+/-6 h$}

\section{No uncertainty on release time}

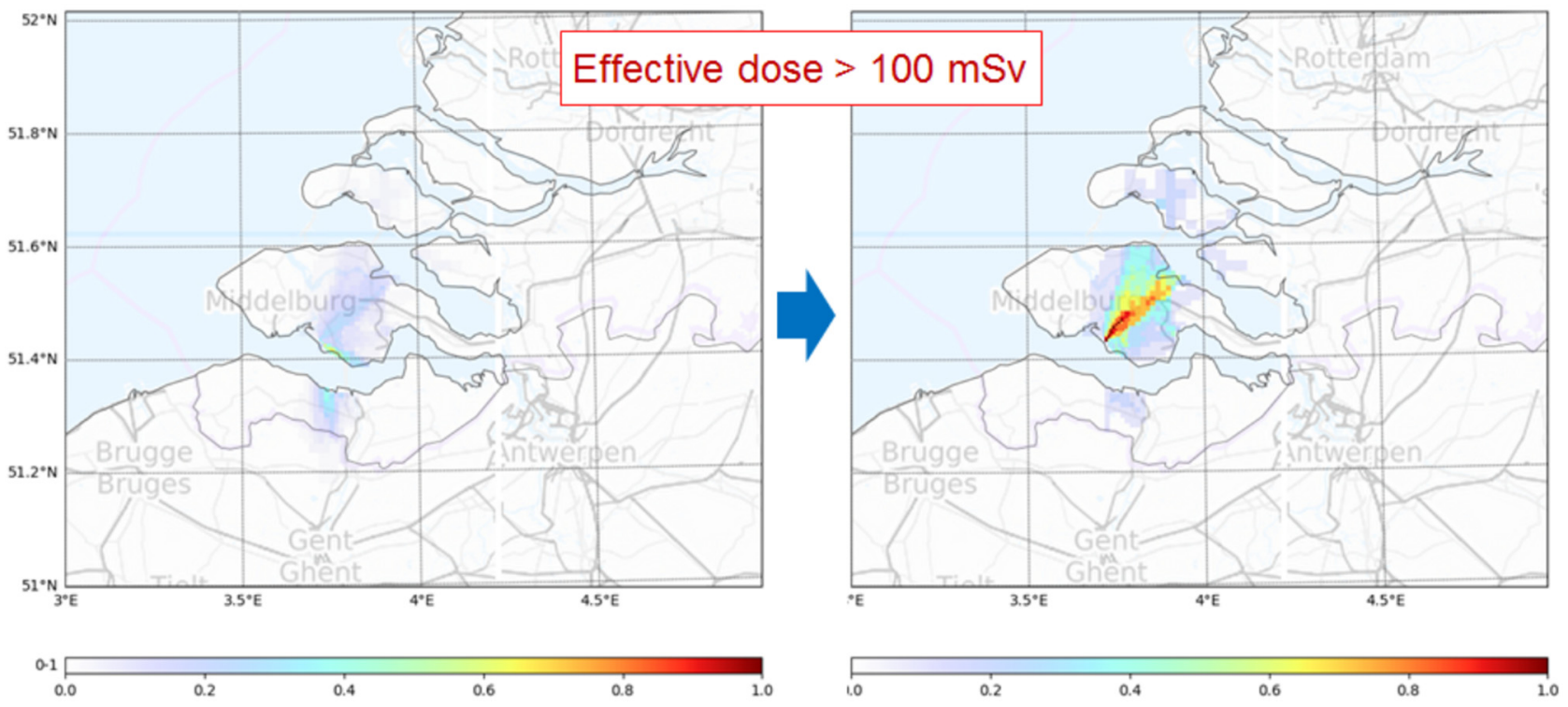

Fig. 12. Comparison of prognostic frequency maps for areas above the threshold value for evacuation: stage 1 with uncertainty in release time (left) and stage 2 without uncertainty in release time (right).

protective action (levels given in Fig. 5), a map of "frequency of threshold exceedance" was represented. These maps could be interpreted in terms of likelihood that a given area could be affected by a dose above the given threshold (Fig. 7).

The frequency maps showed the areas that would "most probably" be affected by the accidental release, however, they were not able to provide a view of the plume footprint that may actually occur. To complement this, example maps of particular simulations (that is, possible outcomes) were provided. The focus was on the "least severe" and "worst case" scenarios in terms of population within the area of threshold exceedance. Out of the 50 simulations (called ensemble members) representing different possible situations (and combined into the frequency maps presented in Fig. 7), the "worst case" was corresponded to simulation number 41 and the "least severe" to member 29. Figure 8 shows the maps of effective dose resulting from these two simulations. The map of the "least severe" case presents a plume footprint located southeast of the release location, which corresponds to a release occurring after the wind direction change. The "worst case" map shows an area of threshold exceedance in the north-eastern zone. The former is within the area of higher frequency of threshold exceedance, whilst the latter corresponds to a lower frequency (Fig. 7). In other words, there was a smaller chance that the "worst case" scenario occurs but, if it did, the consequences would be more severe than for more "probable" scenarios. 
Frequency Plot

No data assimilation
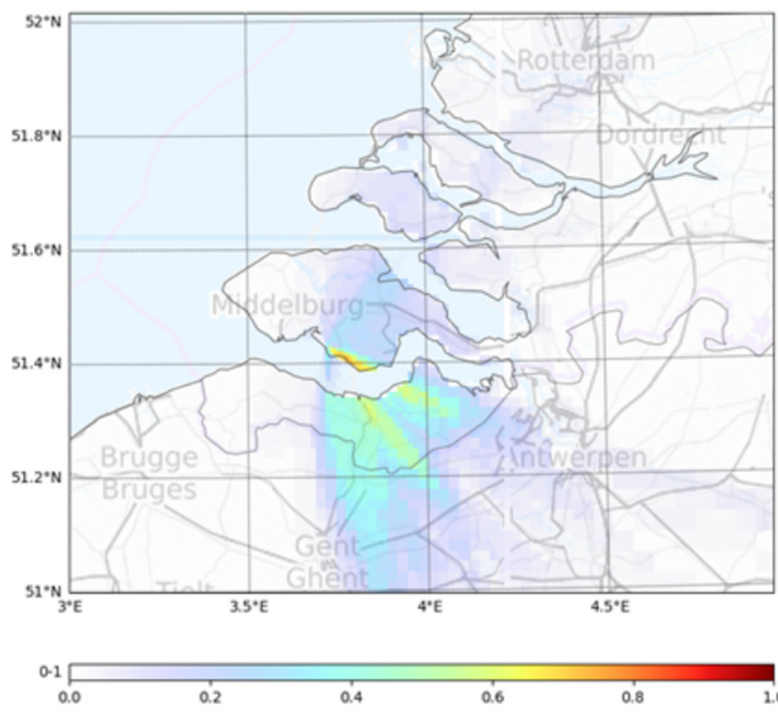

Frequency Plot

No data assimilation

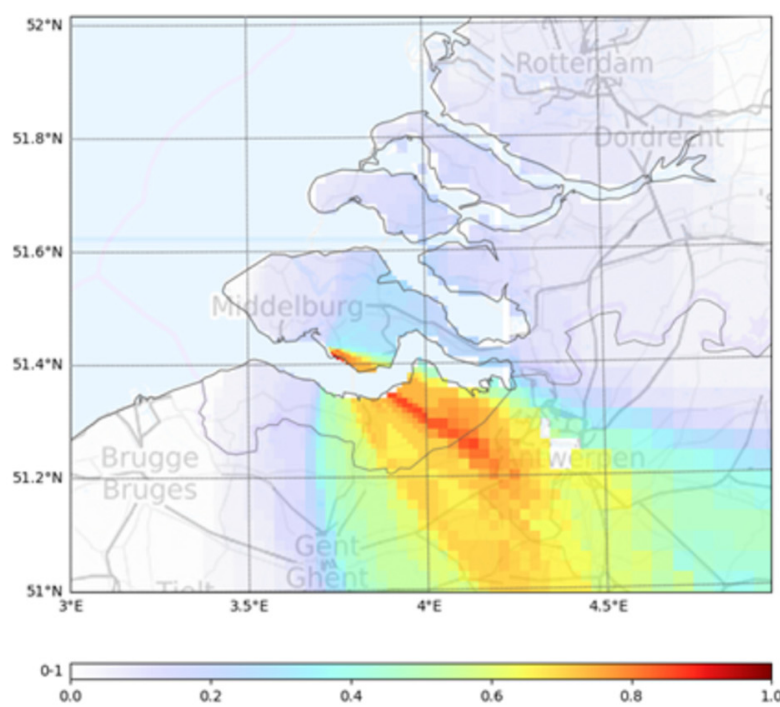

Frequency Plot

With data assimilation
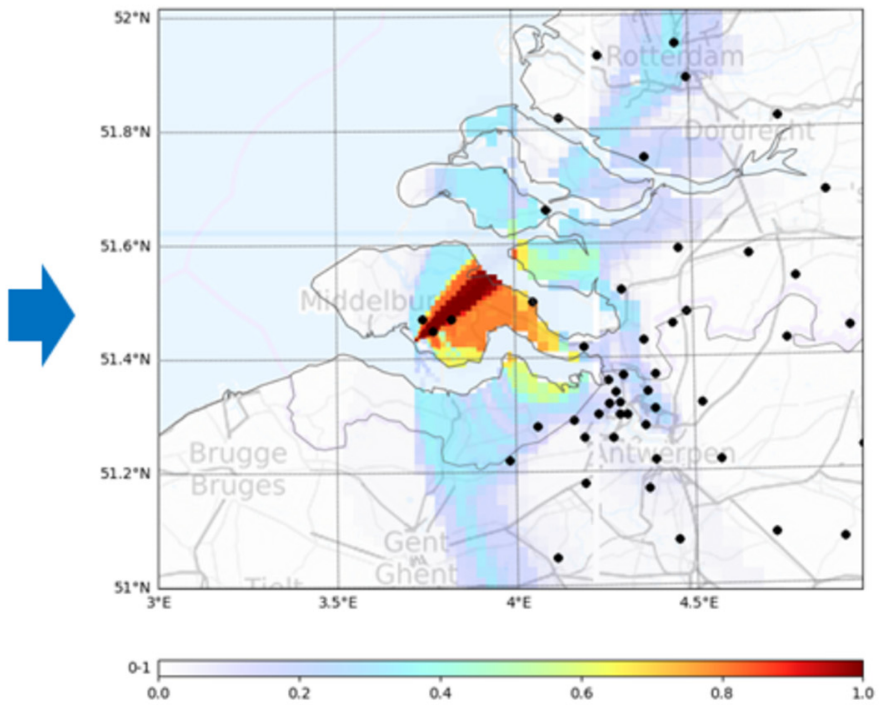

Frequency Plot

With data assimilation
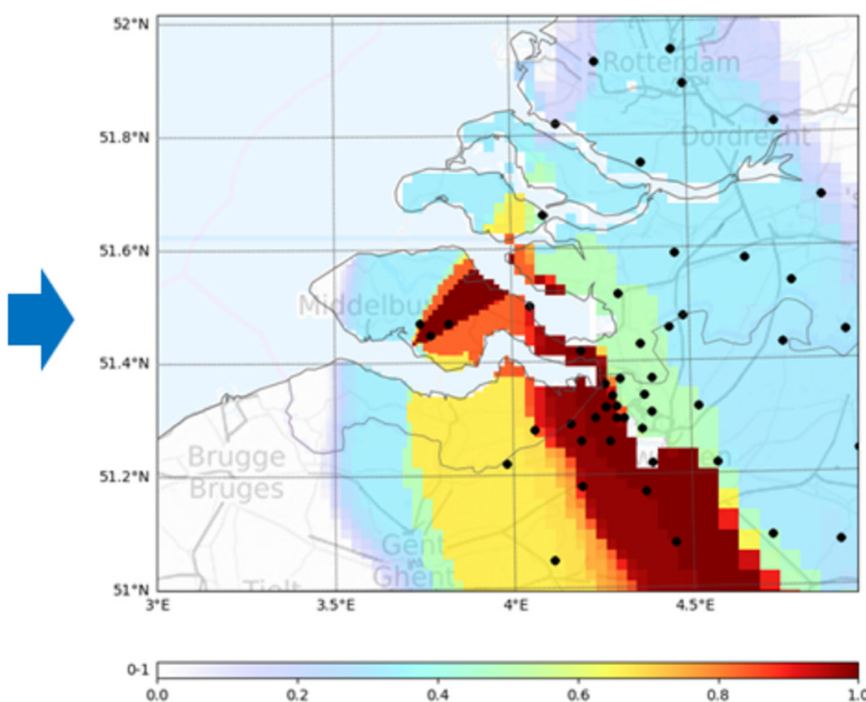

Fig. 13. Frequency maps for effective dose $>10 \mathrm{mSv}$ (top panels) and iodine in milk $>500 \mathrm{~Bq} / \mathrm{kg}$ (bottom panels), without (left) and with (right) data assimilation.

\subsubsection{Feedback from WP1 stage 1 discussion Evacuation}

The main information that participants inferred from the frequency maps (Fig. 7) was the high uncertainty in the direction of travel of the plume. Therefore, the decision to evacuate was assumed to be uniform in all directions (within a given radius) and participants considered only distance from the release (and not direction). Some proposed a radius of $5 \mathrm{~km}$ if resources permit.

They expressed a need for information on site plan, location of evacuation shelters, resources, vulnerable people, planning zones (and actions already decided within this zone) and tourist numbers.

\section{Sheltering}

Participants used frequency maps and population maps, but had more difficulty reaching a decision. Some proposed to wait for more information (e.g. on the plume direction) before issuing a message, others proposed to recommend "preparation for sheltering".

They discussed the timing of the message, for instance, to avoid rush hours and panic. They suggested issuing the message to shelter when most people were already at home.

Some separated the information given in the maps into 2 different areas: high probability/low consequence, and low probability/high consequence. 


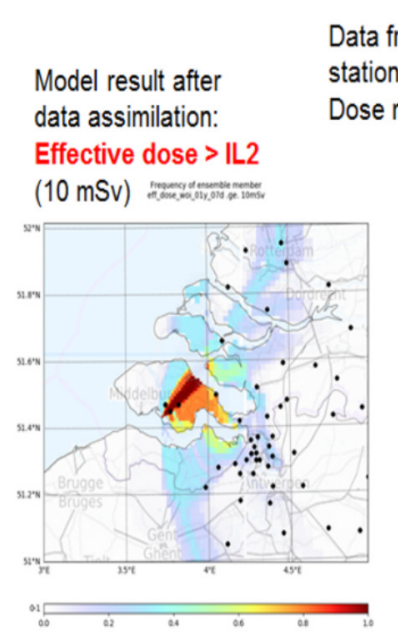

Data from stationary monitoring Dose rate $\mu \mathrm{Sv} / \mathrm{h}$

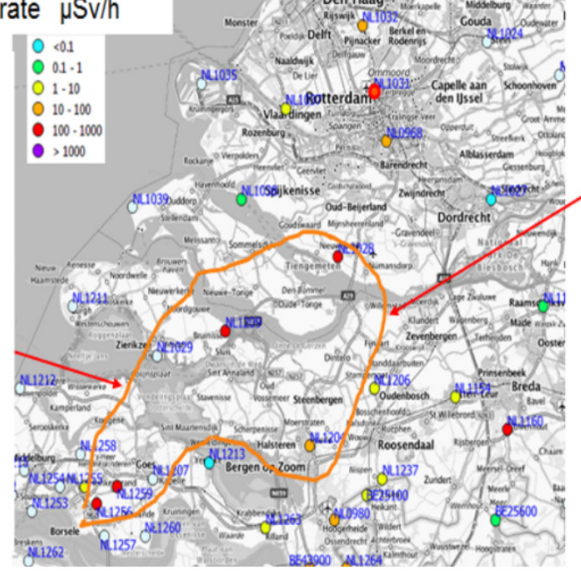

Populated area:

Effective dose $>$ IL1 $(100 \mathrm{mSv})$

Dose rate $>$ OIL1 $=1000 \mu \mathrm{Sv} / \mathrm{h}$

evacuation - relocation?

Effective dose > IL2 (10 mSv)

Dose rate $>$ OlL2 $=100 \mu \mathrm{Sv} / \mathrm{h}$

sheltering - relocation?

Populated area:

Dose rate $>$ OIL3 $=1 \mu \mathrm{Sv} / \mathrm{h}$

improving data base for dose

assessment

Fig. 14. Updated combination of model results and monitoring data: additional information from mobile dose rate monitoring in indicated area (gray or orange line) needed for decision on sheltering and relocation.

The audience expressed a need for information on crossborder agreements between the neighbouring countries possibly impacted and how to coordinate transboundary messages.

\subsubsection{WP1 scenario-based discussions: stage 2}

In this second phase of discussions, the estimated time to release was 12 hours and the release date was known to be 12/07/ 2017 at 15:00 UTC (Fig. 9). The objective was to review the decisions made during stage 1 for sheltering and evacuation (Fig. 10). Additionally, food restrictions were considered (Fig. 11).

No uncertainties remained on the release time. The meteorological uncertainty was still represented by the 10 meteorological members.

This led to a very different prognosis frequency map of threshold exceedance, where the plume footprint was clearly north-northeast of the release location (Fig. 12).

Within stage 2, the questions in relation to evacuation and sheltering were addressed (see Fig. 10), whilst taking into account decisions made previously.

The focus on food restriction was driven by the following questions given in Figure 11.

\subsubsection{Feedback from WP1 stage 2 discussion}

\section{Review of evacuation and sheltering decisions}

When considering the updated information, most groups decided to extend the evacuation on a north-eastern sector based on the frequency map (Fig. 12). They discussed the issue of people trapped between the plume and the coast.

Several groups decided to instruct sheltering across a 50$\mathrm{km}$ zone. Some pointed out that, even if there was a more certain wind direction, the uncertainty (coming from meteorology) shown in the map was still high enough to have an impact on the decision making process.

They discussed the methods of implementing sheltering, with recommendations such as collecting children from schools, provision of access to bottled water and food (not freshly harvested). The conditions for lifting sheltering order were also discussed. For instance, issues about how long people could stay indoors and what should be allowed or not after lifting the order to shelter, were raised.

\section{Food restrictions}

During the short time devoted to discussing food restriction, most groups decided to tell people not to eat freshly harvested food in sheltering zones. They also decided that recommendations to feed cattle on stored food and to shelter them should also be issued in sheltering areas. In the evacuation zone, issues about milking cows were raised. In the background materials, some maps featured probable threshold exceedance of food contamination within areas where no sheltering was planned (not shown in this article), which raised a communication issue relating to the formulation of a food ban message without implementing other protective actions.

\subsection{Reduction of uncertainty in dose assessment for improving situation awareness and risk estimation (WP2)}

The demonstration of tools developed in WP2 focused on health risk assessment and its implications for decision making in the early phase, data assimilation and monitoring strategy and results. All three aspects will be described in the three following subsections.

\subsubsection{Health risk assessment in the early phase}

The benefit of having a software tool for quick and easy assessment of radiation attributed cancer risk for the general population in the transition phase, based on measured doses can be seen as widely accepted (Walsh et al., 2019, 2020). Therefore, the demonstration focused on the applicability of the same tool for health risk information in the early or threat phase, when doses to population groups are based on prognostic data only, with potentially high uncertainties. For this, the uncertainty in the dose maps for the given scenario was visualized by areas of countermeasures (exceedance of 


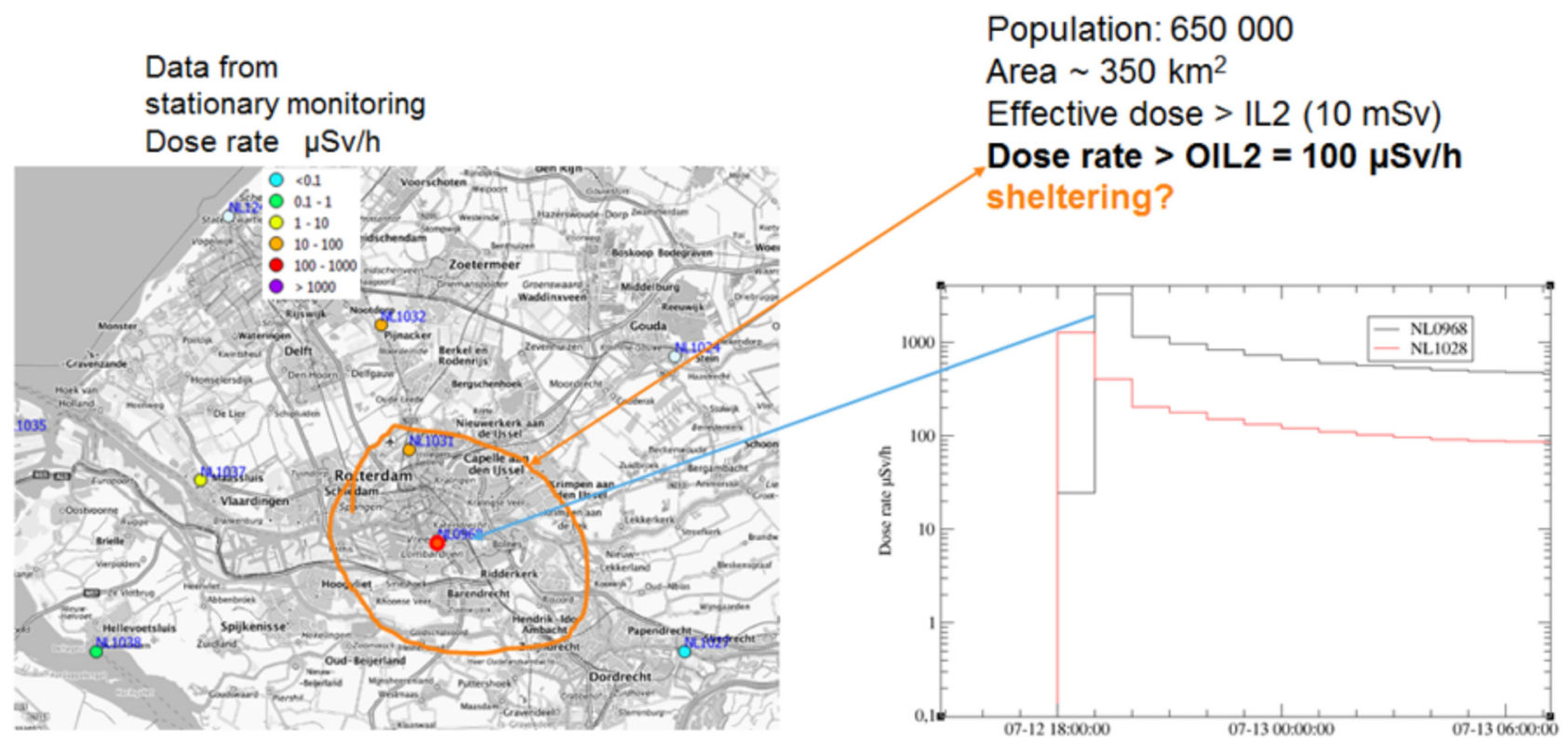

Fig. 15. Updated combination of model results and monitoring data; additional information from mobile monitoring needed for decision on sheltering in urban hot spot region.

10 and $100 \mathrm{mSv}$ ) for given percentiles of the seven-day effective dose. The percentiles chosen were $10 \%$ (largest areas of countermeasures), $50 \%$ and $90 \%$ (no area of countermeasures). For the three different maps, the number of expected cancer cases, baseline cases and the lifetime fractional risk (Walsh et al., 2019) was then calculated, with uncertainty, taking into account the expected dose reduction by the respective countermeasure. This was done for a few cancer outcomes and three age groups of the general population, in order to limit the amount of information to be displayed and considered. Full details will be given elsewhere (Woda et al., in prep.).

Following the demonstration, the participants of the workshop were asked to discuss in groups the issue of the countermeasures based on dose and health risk information, focussing on, amongst other questions, whether or not they find the health risk information to be useful and if they would recommend decision makers to consider the health risk implications.

\subsubsection{Data assimilation}

With first monitoring data available, data assimilation can be performed to contribute to better characterisation of the situation and to better support decision making. Especially in the early phase, data from atmospheric dispersion calculations and data from the first and typically sparse radiological measurements can be combined using data assimilation techniques. The data assimilation model used in this work is based on an Ensemble Kalman filter (EnKF). Results of the data assimilation using an EnKF are illustrated in Figure 13. Frequency maps of threshold exceedances for effective dose greater $10 \mathrm{mSv}$ (top panels) and iodine in milk greater $500 \mathrm{~Bq} /$ $\mathrm{kg}$ are updated using data assimilation; the updated maps on the right hand side of the panel. The updated maps show an increase of frequency, i.e. probability, of threshold exceedance in the affected areas and therefore a reduction of uncertainty in the frequency maps.

\subsubsection{Monitoring data and monitoring strategy}

As soon as data from stationary and mobile monitoring are available and assessed they are used for further data assimilation and for making more precise decisions based on the improved assessment of the radiological situation.

Combination techniques for prognostic results and monitoring data are needed to reduce uncertainties in decision making process in urgent and early response phase.

The assumed monitoring data also showed local features, which were not predicted by any of the ensemble members. Additional mobile monitoring data are needed to reduce uncertainties for dose assessment for different critical tasks for protecting population in the early response phase of an accidental release scenario:

- task 1 - Population living in regions, where assessed dose exceeds dose intervention level for relocation. Additional information from mobile dose rate monitoring help to reduce uncertainties in the corresponding decision making process;

- task 2 -Population living in regions, where assessed dose exceeds dose intervention level for sheltering. Additional information from mobile dose rate monitoring help to reduce uncertainties in the corresponding decision making process (see Fig. 14);

- task 3 -Population living in regions, where potential hot spots are indicated e.g. due to wet deposition. Additional information from mobile dose rate monitoring help to reduce uncertainties in dose assessment (c.f. Fig. 15).

The discussion on monitoring strategies focused of the following points:

- Which monitoring strategies would you recommend?

- Will your strategy be based on prognostic or existing observation data?

- Which areas will be prioritised? 


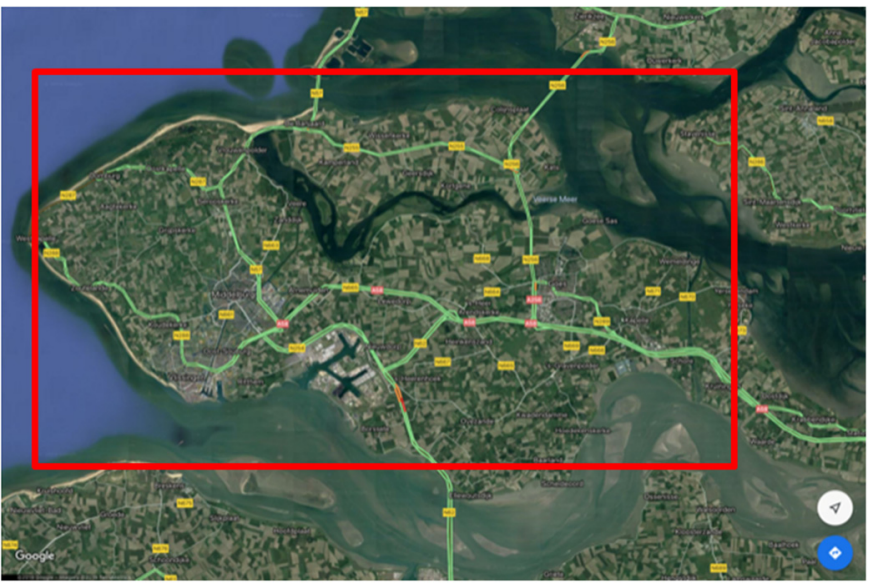

Fig. 16. Area for demonstration of process-based modelling.

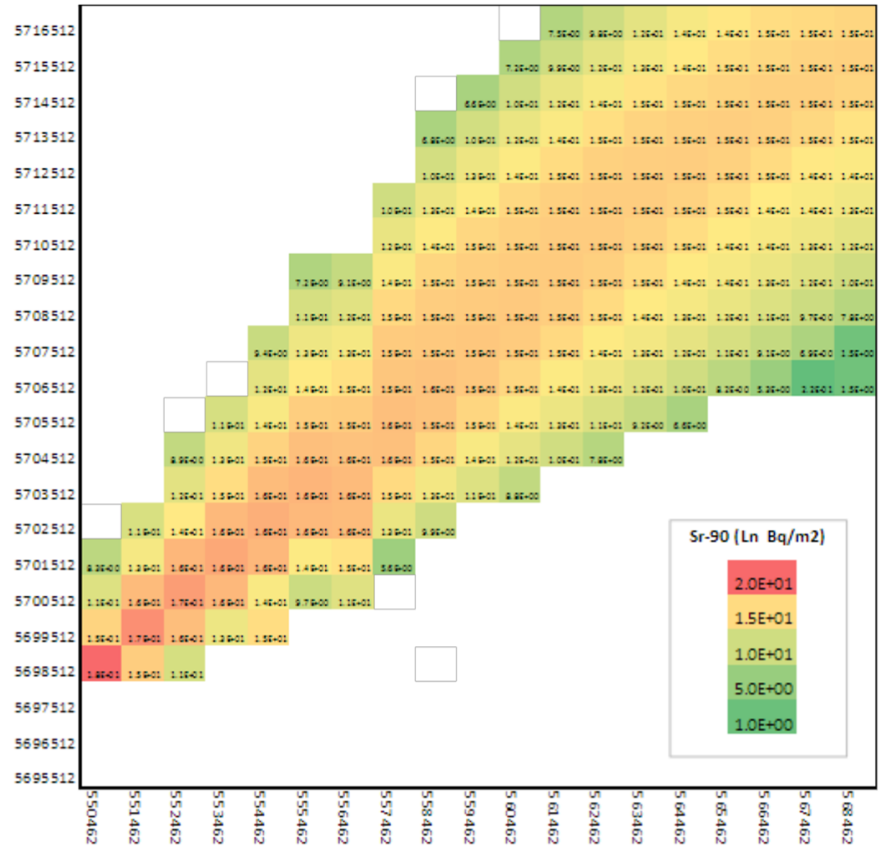

Fig. 17. Deposition map for ${ }^{90} \mathrm{Sr}\left(\mathrm{Bq} \mathrm{m}^{-2}\right)$ used in the assessment. Note: the values are reported as natural logarithm, $\ln$ (deposition). Each cell covers an area of $1 \mathrm{~km}^{2}$ (from Brown et al., 2020).

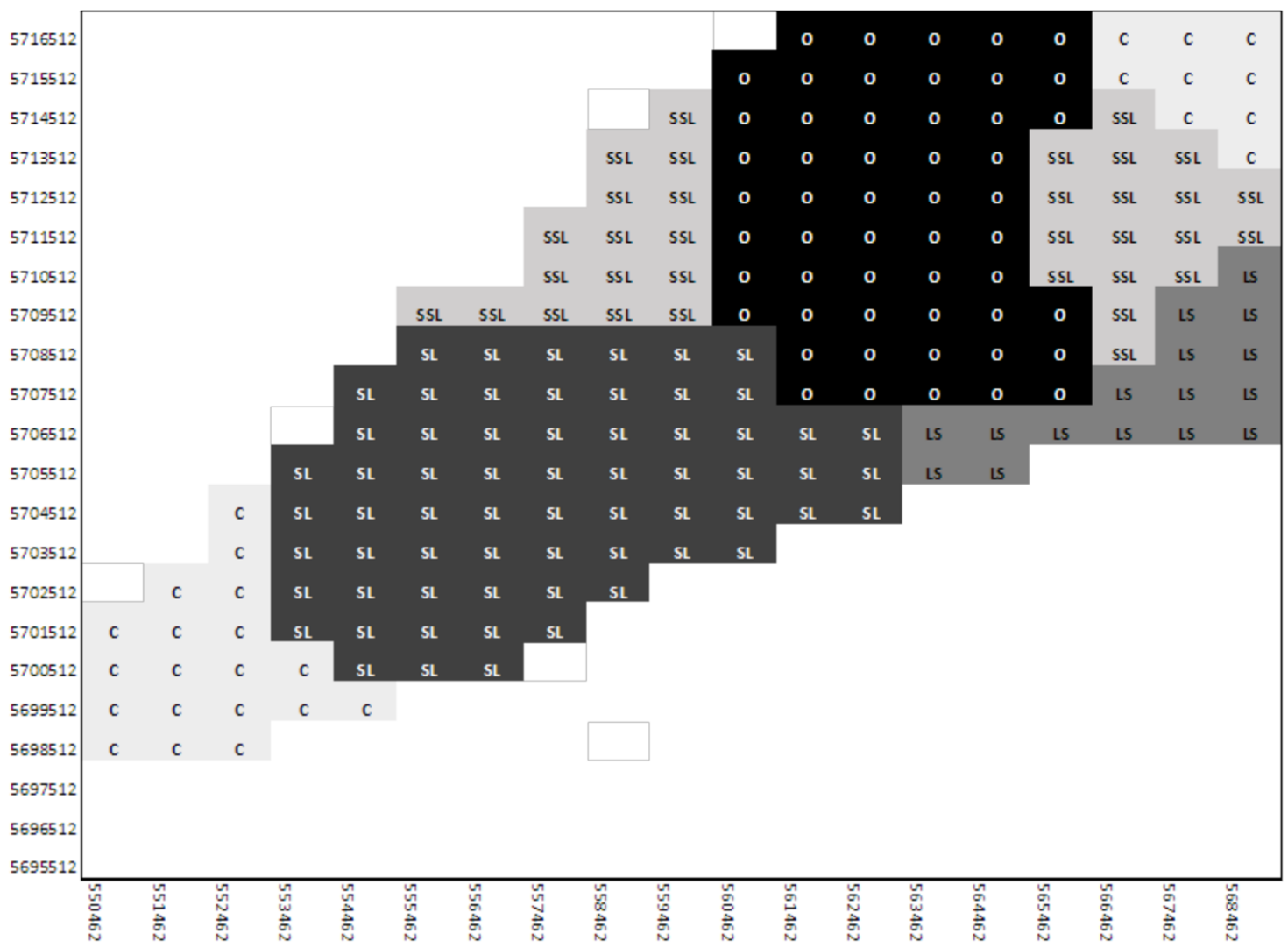

Fig. 18. Soil property data and soil map showing the grid of spatial soil categorisations (C: clay; SL: sandy loam; SSL: sandy silty loam; LS: loamy sand; O: organic) as used in the assessment (note this has been fabricated for demonstration purposes; from Brown et al., 2020). Cell size equates to $1 \mathrm{~km}^{2}$. 


\subsubsection{Feedback from WP2 scenario-based discussions}

Concerning the health risk assessment, there was an unanimous feedback by the participants that this information is generally important but there were reservations of applying this tool in the early phase based on prognostic data only. However, it was suggested that the health risk tool could be very useful for communication to the public and to balance the positive and negative effects of the respective countermeasures. More details are given in Woda et al. (in prep.).

With regard to the monitoring strategy, workshop participants stressed the importance of mobile versions of the detectors and remarked that this should also include unmanned aerial and ground vehicles (drones and robots). The overall opinion was that the monitoring strategy and decision should be based on prognostic data but that the observed data, as soon as they are available, should be used to adjust the recommendations. Monitoring data are also needed to decide if the countermeasures can be lifted. Although measurements should focus on the prioritized areas, monitoring outside these areas was also recommended by the participants to confirm that the level of contamination is truly negligible or zero.

\subsection{Radioecological modelling: fit for purpose (WP3)}

The outputs of WP3 were reviewed (see Beresford et al., 2020) with the focus being on the development of processbased soil-plant models and their application to the Borsselle scenario.

The demonstration compared predictions of the FDMT (Food Chain and Dose Module for Terrestrial Pathways) module in the JRODOS decision support system to processbased models focusing on predictions for ${ }^{90} \mathrm{Sr}$ and ${ }^{137} \mathrm{Cs}$ in grass and milk. The default parameters of FDMT were used, with the model being implemented in the ECOLEGO platform (see Brown et al., 2019, Brown et al., 2020). The effect of K-fertilisation on radiocaesium transfer to milk and grass was also considered. The area of the scenario used for this demonstration is presented in Figure 16. Figure 17 presents the deposition pattern over the study area and, Figure 18, for demonstration purposes, a fabricated soil distribution map with soil characteristics data. Figure 19 presents a comparison of results using a soil-plant processedbased model for different soil types with predictions using the default FDMT model.

\subsubsection{Feedback from WP3 scenario-based discussions}

The scenario-based presentations demonstrated that:

- process-based soil-plant models could be used for Cs and Sr to identify areas of longer-term comparatively high (or low) transfer and hence better focus remediation effort (Fig. 19, top);

- process-based models generally offer no appreciable benefit for short-term predictions (as interception etc. dominates and root uptake is minor).

Process-based soil-plant models have some potential to model soil based countermeasures (see Brown et al., 2020); however, more work is required on how to implement (and test)
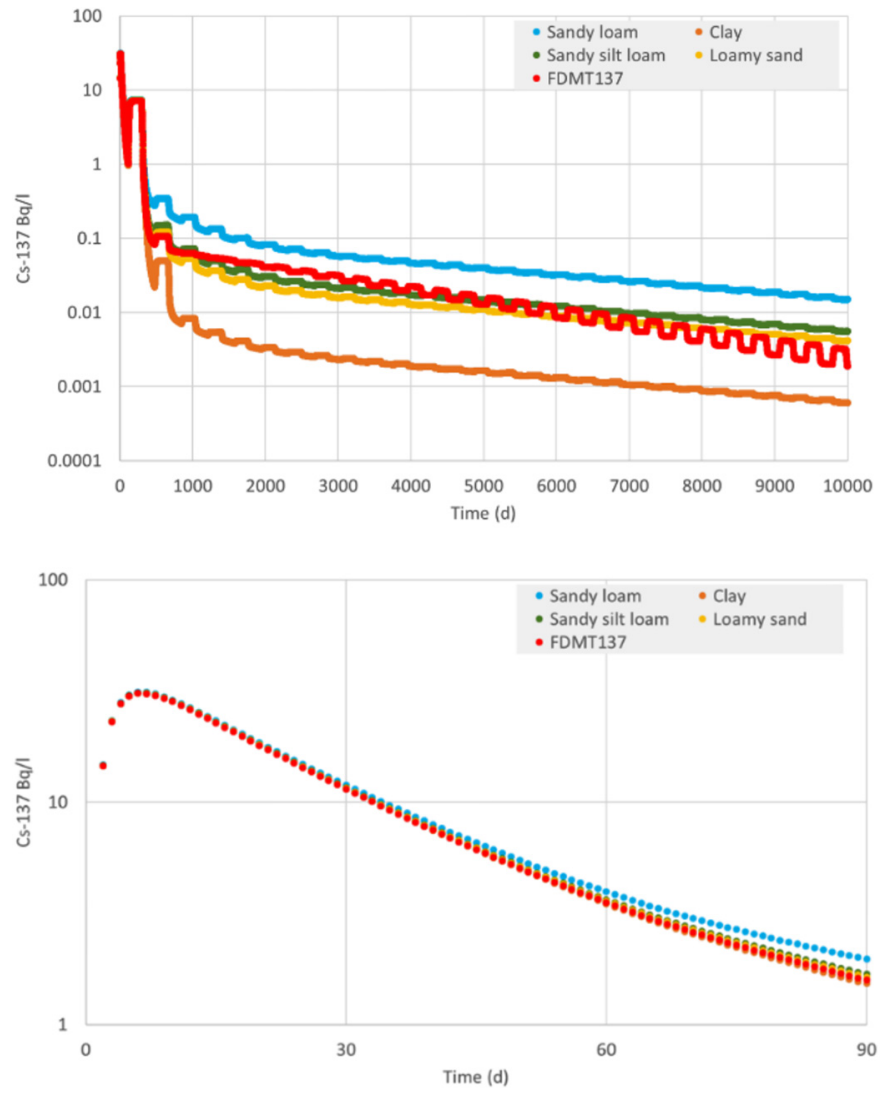

Fig. 19. Predictions of ${ }^{137} \mathrm{Cs}$ activity concentrations in milk using a process-based soil-plant model for the different soils types; for comparison predictions using FDMT are also given. Top: predictions over 27 years; bottom: predictions over the first $90 \mathrm{~d}$ after deposition. Note: an expanded and refined application of the Sr and Cs soil-plant process-based models to the Borsselle scenario is presented and discussed in Brown et al. (2020).

this. Similarly, there is a general need to test, and where required, improve the existing process-based soil-plant models.

A poster was presented at the dissemination meeting describing the findings and conclusions of a workshop, "Do process-based models have a role in human food chain assessments?" (September 2019, Madrid) which was attended by about 40 end-users (industry, regulators, international bodies) and scientists, (see Beresford et al., 2020; Duranova et al., 2020).

\subsection{Transition to long-term recovery, involving stakeholders in decision-making processes (WP4)}

The fourth block in the workshop was dedicated to addressing the issues and uncertainties arising in the management of the response, and the recovery preparedness carried out by decision-makers, including the stakeholders, during the transition phase. The situation in this period requires of some specific efforts to conclude the emergency response and establishing specific response plans to begin the recovery/ long-term rehabilitation of the affected areas, supporting the 


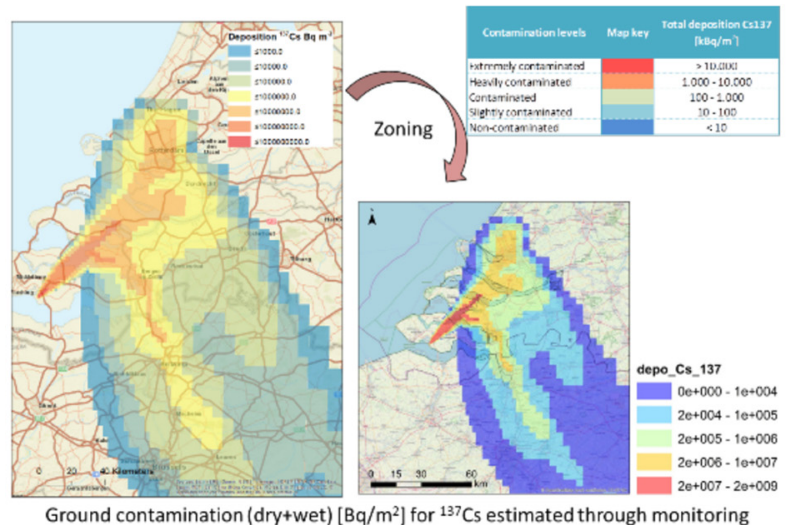

Ground contamination (dry+wet) $\left[\mathrm{Bq} / \mathrm{m}^{2}\right]$ for ${ }^{137} \mathrm{Cs}$ estimated through monitoring

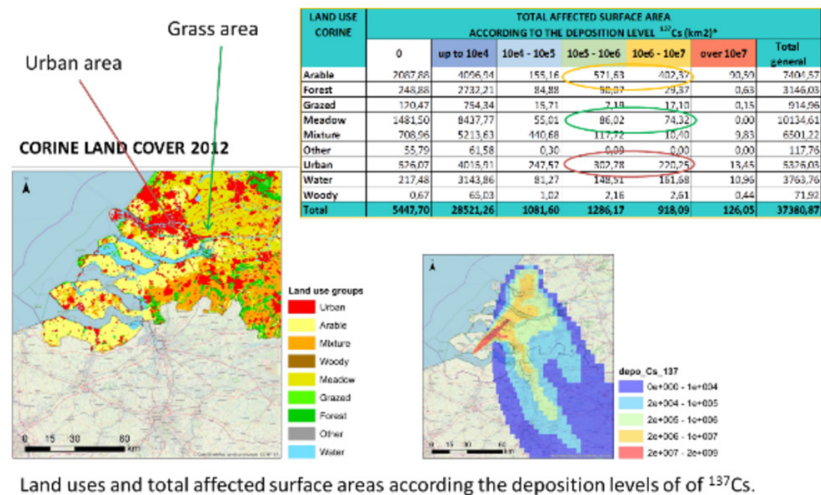

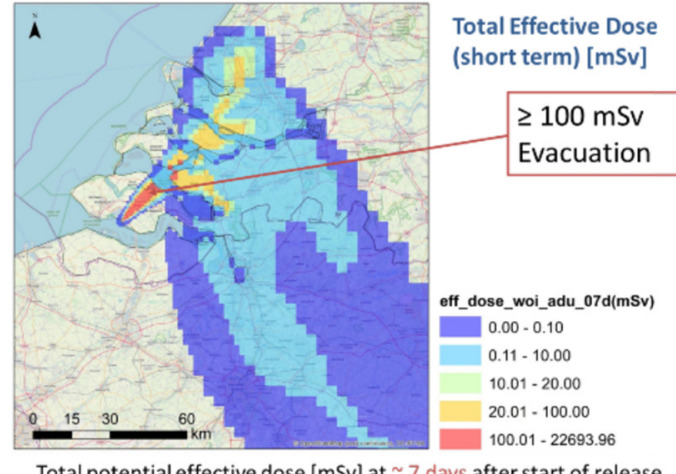

Total potential effective dose $[\mathrm{mSv}]$ at $\sim 7$ days after start of release

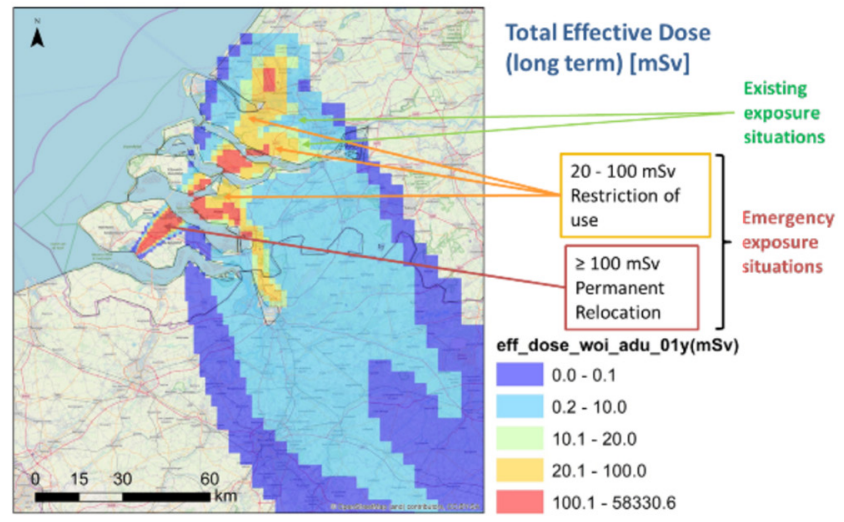

Total potential effective dose, except ingestion [mSv] at 1 year after start of release

Fig. 20. Information on the radiological and environmental situation of the affected areas by the accidental deposition of ${ }^{137}$ Cs.

return to normal social and economic activity, as far as possible.

Two sessions were envisaged: the first, as a scenario-based facilitated discussion, to demonstrate the development of action strategies in both agricultural and urban scenarios, and the second, to present the set of guidelines and recommendations elaborated in WP4 to improve the decision making process during the transition phase.

\subsubsection{WP4 scenario-based facilitated discussion}

The intervention scenario in the transition phase was based on these main assumptions:

- the release has ceased, the control over the source has been taken and urgent protective measures have been implemented to avoid the exposure to population, including evacuation, access restrictions and food restrictions;

- the radioactive contamination has spread in the surroundings of the damaged nuclear power plant and transported and dispersed through near regions, affecting both inhabited areas and relevant agricultural and farming systems;

- the contamination level range and the affected areas have been identified;

- it has to be decided how to proceed in such a situation. The actions to be taken will be focused on mitigating the consequences of the contamination and on preparing recovery plans on the urban and agricultural areas and the food-chain system affected.
For the purposes of this session, one member of one ensemble from WP1 was assumed to be the "real" deposition pattern. Only the ${ }^{137} \mathrm{Cs}$ contamination was considered.

The main question for discussion was: "How to plan the establishment of optimal remediation strategies with stakeholder involvement in the decision-making process?", and the focus in discussions was made on: Involvement of the stakeholders in the decision-making process, and the decision criteria and actions taken in the transition phase.

First, the introduction to the state of the scenario in the transition phase was presented to the audience. Figure 23 shows the information provided to participants on the radiological situation, including zoning maps according to the ground contamination level of ${ }^{137} \mathrm{Cs}$ and according to the dose prognostic at both short (after the total deposition), and long-term (one year after the deposition). These maps illustrate the areas affected, the magnitude of the radiological impact and the preventive actions to take on each one, in case no other action is implemented. In the other way, the Figure 20, also presents a summary of the environmental characterisation, according to the land use zoning, in order to identify the populated (urban) and productive areas of concern.

In summary, the scenario has some zones with an emergency exposure situation, where if the total effective dose projected to $1 \mathrm{y}$ (TED1y) $\geq 100 \mathrm{mSv}$, a permanent relocation is mandatory; and if TED1y is among $20 \mathrm{mSv}$ and $100 \mathrm{mSv}$, some type of restriction of use would be implemented. In these zones, actions 


\section{Urban area of concern}

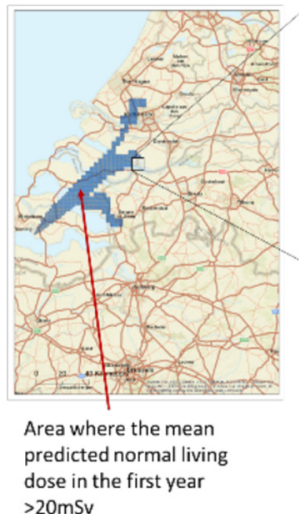

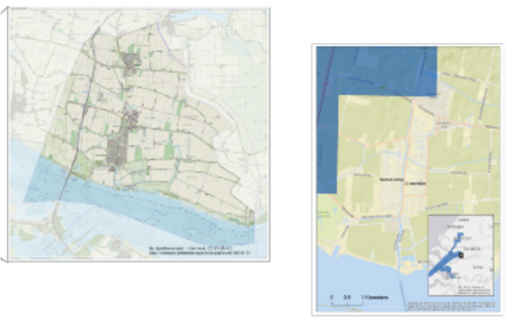

The municipality of Cromstrijen is at the edge of the $20 \mathrm{mSv}^{-1} \mathrm{y}^{-1}$ zone. It consists of the communities Klaaswaal and Numansdorp (townhall).

Fig. 21. The urban area of concern.

trying to reduce the TED1y to $\leq 20 \mathrm{mSv}$ should be planned and implemented in order to look at the conclusion of the emergency phase. Other zones will be under an existing exposure situation because the TEDly is situated among $1 \mathrm{mSv}$ and $>20 \mathrm{mSv}$. Here, optimised strategies should be planned to recover the living conditions as soon as possible.

For purposes of the demonstration, areas in the zone heavily contaminated have been selected: An urban area situated in the most populated zone and with a TED1y $\approx 20$ $\mathrm{mSv}$ and an agricultural system situated in the meadow areas at the North of this zone, in Zuid-Holland.

For each environmental scenario, background information, maps and graphs to deal with the consequence management and preparedness for the recovery were presented to the audience. Following, the urban and agricultural scenarios are presented in detail.

\section{Urban scenario}

The urban area of concern was the municipality of Cromstrijen, at the edge of the $20 \mathrm{mSv} \cdot \mathrm{y}^{-1}$ zone. Figure 21 shows the location of this municipality and its main characteristics, population, surface areas and the predominately built environment.

As consequence of the deposition of ${ }^{137} \mathrm{Cs}$, there are different contaminated surfaces: roofs, walls, streets, pavements, gardens as other areas of grass, playing grounds, sports fields, interiors, and so on. The contamination average is around $1 \mathrm{MBq} \mathrm{m}^{-2}$ for ${ }^{137} \mathrm{Cs}$ and the doses range $20 \mathrm{mSv} \mathrm{y}^{-1}$. A set of options for recovery strategy development were agreed to be following as it is shown in Figure 22 .

The consequences for health (projected residual doses in Numansdorp, mean individual dose 1st year due the recovery strategies, number of cancer incidents during 50 years attributed to the exposure (population and workers)), costs and waste were estimated and evaluated from the values used in the WP4 Dutch panel ${ }^{1}$ (van Asselt et al., 2019) and using the approaches developed in the WP4 task 4.1 (Charnock et al., 2020). The results were shared with the audience as a starting

\footnotetext{
${ }^{1}$ WP4 internal information and data provided by C. Twenhöfel, RIVM, 2019.
}

\section{Municipality Cromstrijen / Numansdorp}
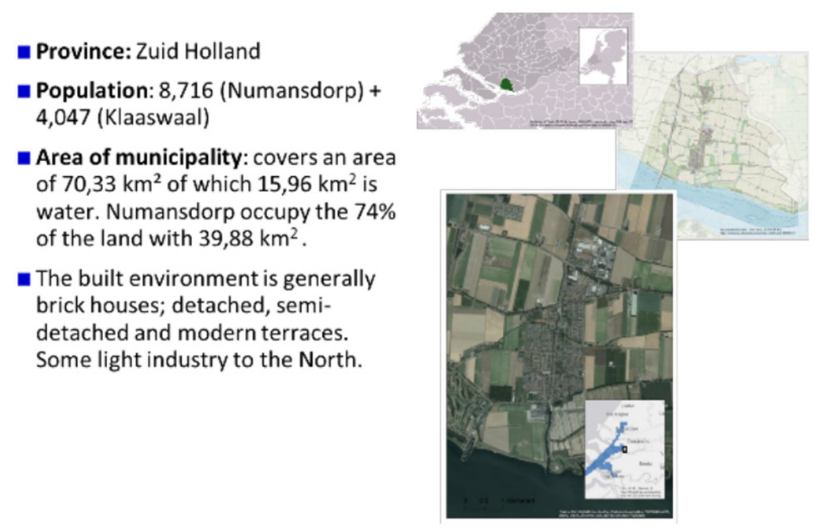

Fig. 22. Options for recovery (strategies) in the urban area.

point of the discussions (some examples are shown in Fig. 23). A table summarising the quantifiable consequences of cleanup was also provided.

It was pointed out that also other factors, which are more difficult to quantify, should be also taken into account to assess the success of the strategies. The biggest uncertainty was assumed to be probably in how much the consequences of the accident in other regions will impact on this town, i.e. disruption to supply chains, employment availability and customer demand. Among other factors could be psychosocial consequences, prevent anxiety, acceptance of the protective actions and recovery strategy, perception of the risk for the consumer, protection of export, independence population, trust on the authorities and other.

\section{Agricultural scenario}

For the agricultural scenario, the affected areas were characterized as it is given in Figure 24.

Contamination and transfer to soils, crops and food-chain (products), estimated using the modules of JRODOS (Raskob et al., 2011) have been presented and discussed under the scenario in Zuid-Holland. In this area, the contamination ranges among 1 to $10 \mathrm{MBqm}^{-2}$ for ${ }^{137} \mathrm{Cs}$. There are some products with activity concentration above the maximum permitted level (MPL) for commercialisation (i.e. $\geq 5000 \mathrm{~Bq}$ $\mathrm{kg}^{-1}$ in grass; $\geq 1000 \mathrm{~Bq} \mathrm{~kg}^{-1}$ in milk). The temporal evolution of the activity concentration of ${ }^{137} \mathrm{Cs}$ in agricultural products 


\section{Predicted residual external dose (Numansdorp/Cromstrijen)}
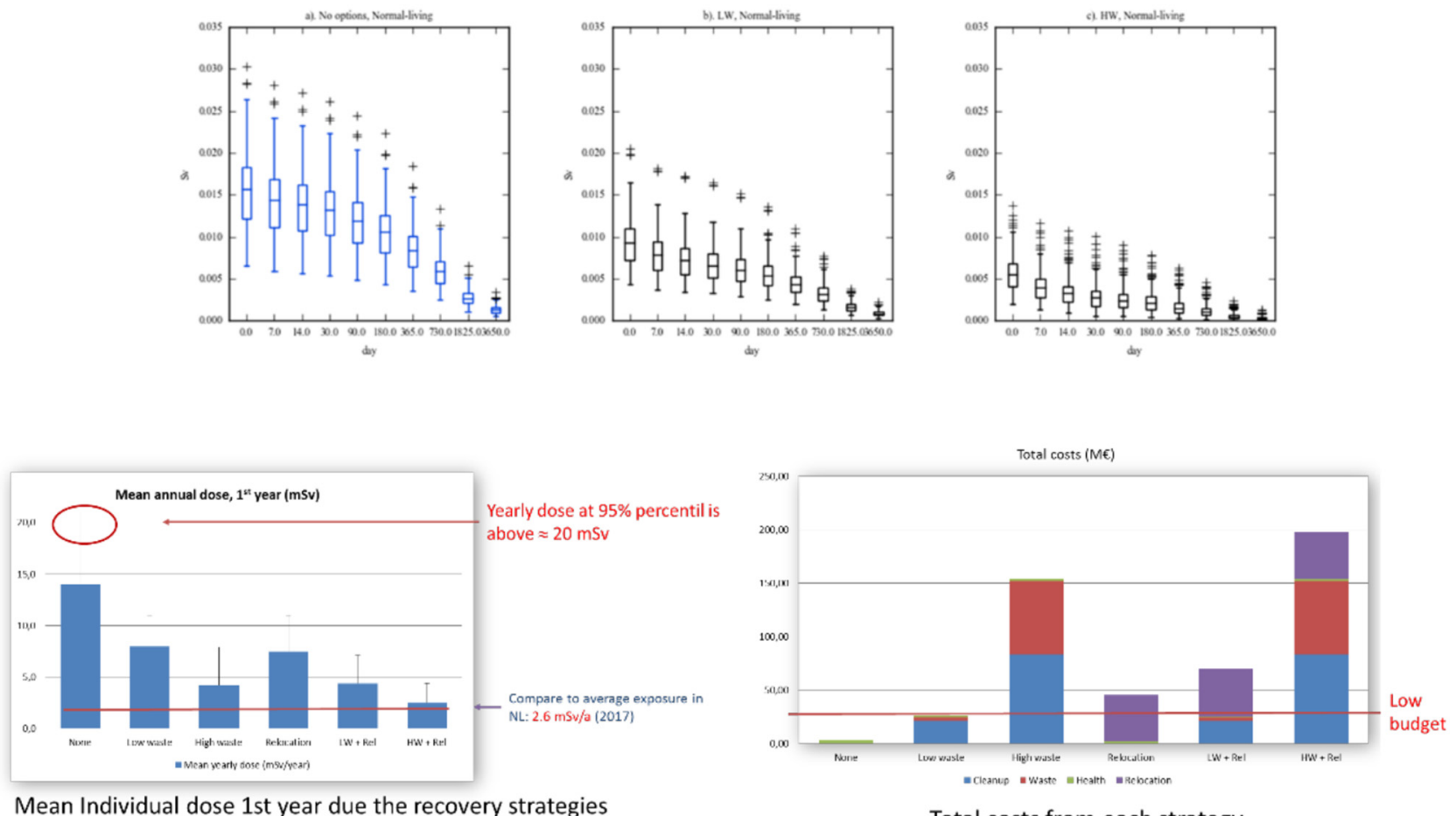

Total costs from each strategy

Fig. 23. Information on the consequences of implementing different recovery strategies in the urban areas in terms of the temporal evolution of the residual doses, mean annual doses (1st year) and costs of the strategies.

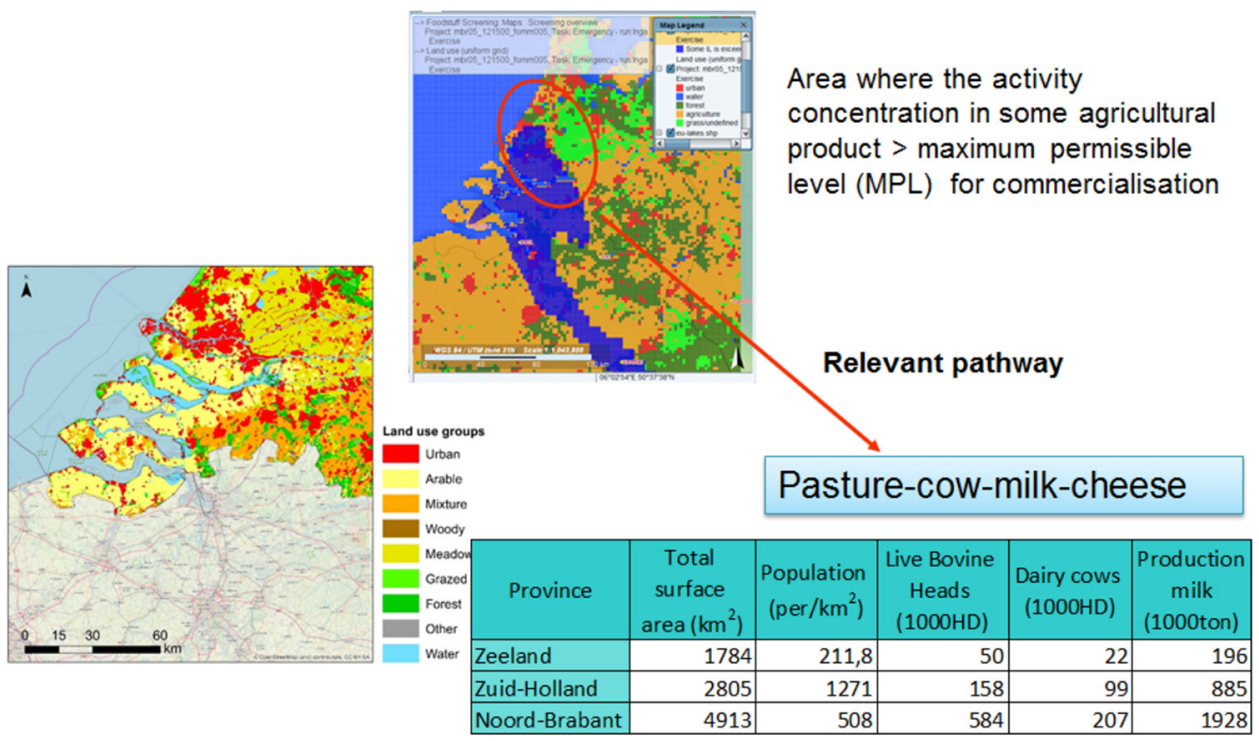

Fig. 24. Agricultural areas of concern.

presented to participants and taken into account in discussions is given in Figure 25.

A set of recovery alternatives was selected from the EURANOS handbooks (Nisbet et al., 2010) for discussion and is presented in Figure 26.

The WP3 outputs on recovery actions in the soil as it is presented in Figure 27 have been used as an input for discussions.
Additionally, to the uncertainties presented above due to parameterisation or modelling of the alternatives of recovery (Charnock et al., 2020), there are other uncertainties, inherent to the decision making process, that rise when planning the implementation of a recovery strategy. A summary of the main uncertainties, identified from the WP4 stakeholders' panels (Montero et al., 2020) was presented to facilitate the discussions in the working groups as follows from Figure 28. 

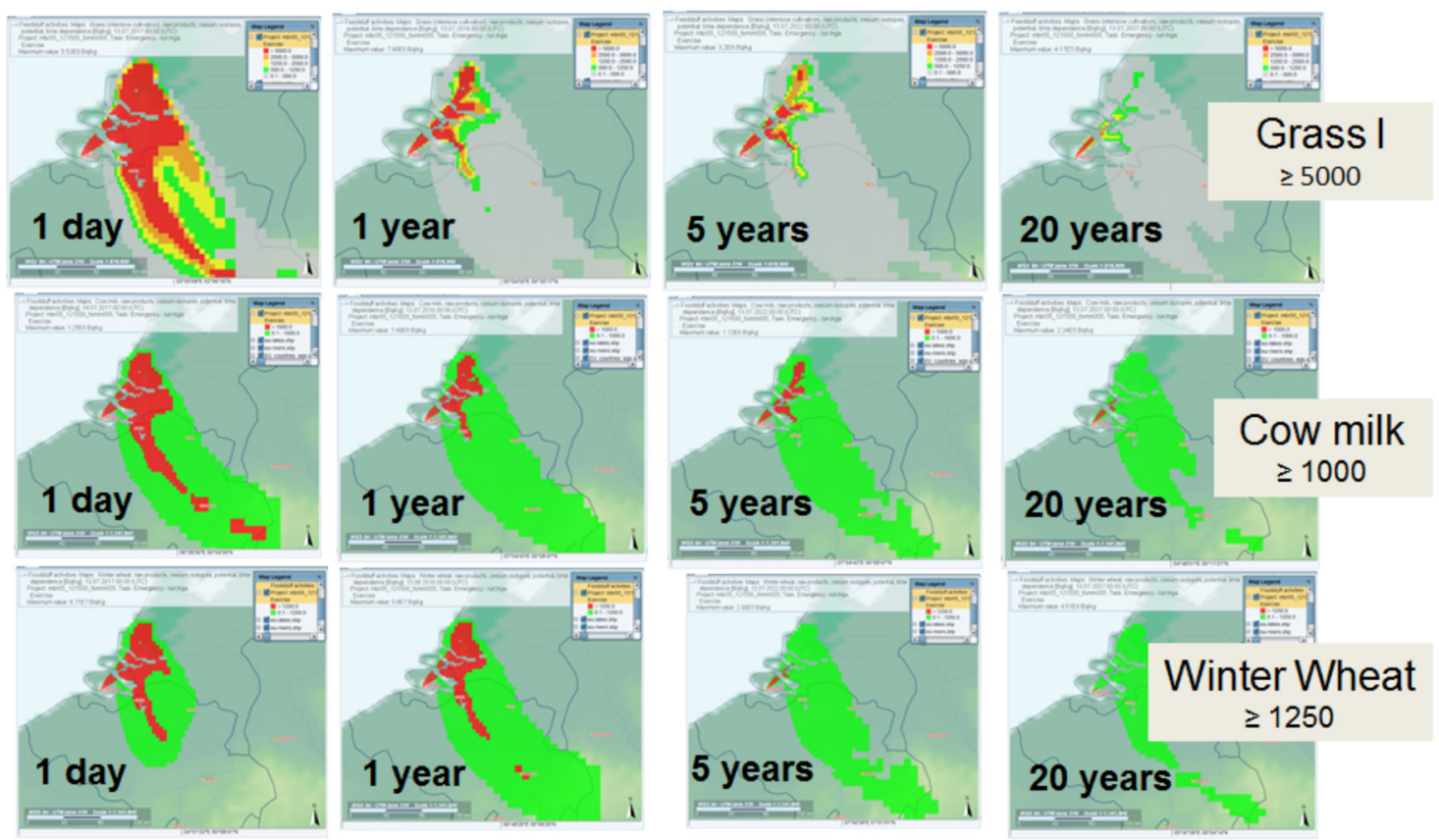

Fig. 25. Temporal evolution of the activity concentration of ${ }^{137} \mathrm{Cs}$ in agricultural products: Zoning according to the MPLs $\left[\mathrm{Bq} \mathrm{kg}^{-1}\right]$.

- Do nothing, implementing a monitoring strategy
- On the Soil, to reduce the transfer of contamination to the food-chain:
- Mechemical treatments: Application of Potassium fertiliser
- Deep ploughing
- Top soil removal
- On the cattle, to reduce the activity concentration on the animal products:
- Supply clean fodder
- Administration of AFCF
- On the foodstuffs:
- Proccesing of milk for human consumption

Fig. 26. Recovery alternatives in the agricultural area of concern.

- Issues in the agricultural environments
- Zoning? Constrains? Reference levels?
more vulinerable
- Prognostic versus monitoring results? In which cases should these results be used?
How to obtain a balanced use?
- Selection and establishment of strategies. How to apply the optimisation principle?
- Effects influencing the decision and future evolution of scenarios: Social,
Technological, Economic, Environmental, Political and Ethical values. Criteria to
measure them.
How to translate these issues into goals and objectives suitable for the
restoration of agricultural environments?
The cessation of production or restriction in consumption are actions in the
emergency phase, but difficult to keep over time; economic compensation?
Are there enough resources (material, human, economic, technical) to
implement the different options?
What will be the effects on the food distribution chain? Possible socio-
economic impact.

Fig. 28. Uncertainties raised in the planning of the recovery strategies in an agricultural environment.

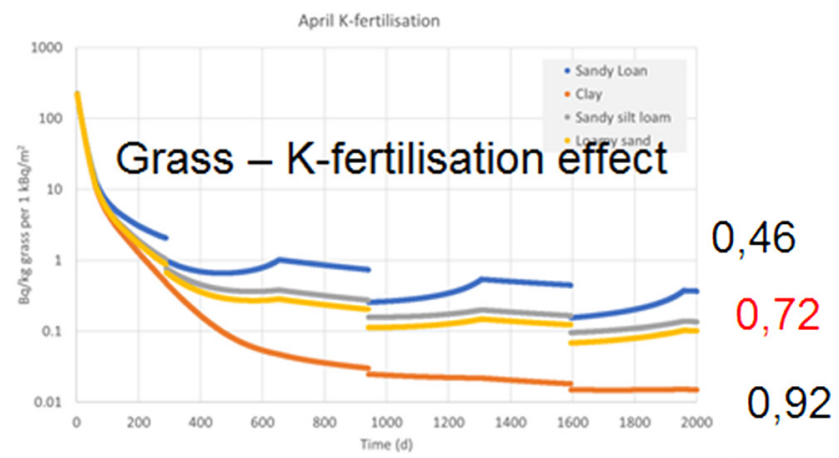

Fig. 27. Recovery actions in soil. 


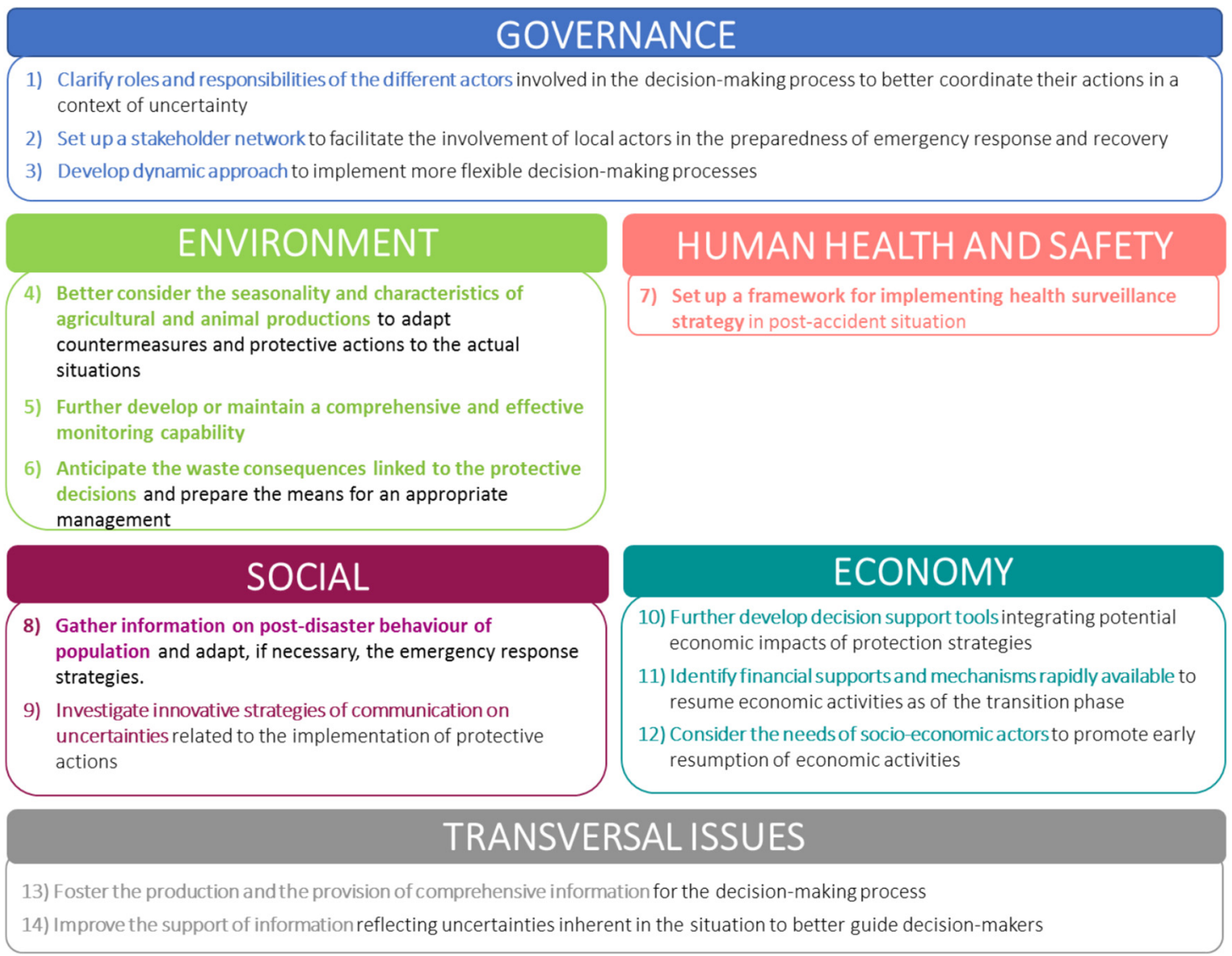

Fig. 29. Recommendations for each category of uncertainties.

\subsubsection{Feedback from WP4 scenario-based discussions}

For better organisation of the discussions, individual groups of 10 people, around a table, were distributed into two parts. Each one was devoted to discuss the issues of one of the two scenarios. The discussions on both scenarios have been driven by a common questionnaire distributed to each group of participants which was split into the following topical questions:

- Q1. Which are the main concerns when facing the recovery strategy?

- Q2. What are the objectives to pursue in the recovery strategy?

- Q3. What are the main factors and key criteria for the strategy selection?

- Q4. What are the main uncertainties affecting the decision about the recovery strategy?

- Q5. Choose the strategy you think it is best according to the previous discussions.

Each question included suggested answers and provided a possibility to complete other suggestions discussed within the working group. Participants indicated the preferences of the main concerns when facing the recovery strategy so it was possible to estimate the most frequent concern. The questionnaire provided the possibility to scale relative importance of the proposed objectives to pursue in the recovery strategy, main factors and key criteria for the strategy selection within the scale from 1-not important to 7-very important. The main uncertainties have been identified within the categories such as governance, environment, human health and safety, social, economy and transversal issues. Based on the discussions some working groups agreed on the strategy they thought is the best.

The questionnaires have been collected and answers from each working group evaluated and provided as an input for the further discussion and demonstration of the WP6 outputs (Sect. 3.6). Positive feedback was obtained from the participants who highlighted the usefulness of using scenario-based analysis to engage different stakeholders in the post-accidental decisionmaking process and to promote discussions where all actors can give their views and preferences on the recovery alternatives. Participants also highlighted the necessity of to provide accurate and understandable information, prepared and focussed to the objectives of the decisions, in order to have a better knowledge on the actual reality and the possible futures helping the decision-making on the recovery actions.

\subsubsection{Guidelines and recommendations for decision making during the transition phase}

The presentations and follow-up scenario-based facilitated discussions in the area of the development of countermeasure strategies involving stakeholders were completed with a poster session focusing on the involvement of stakeholders in 


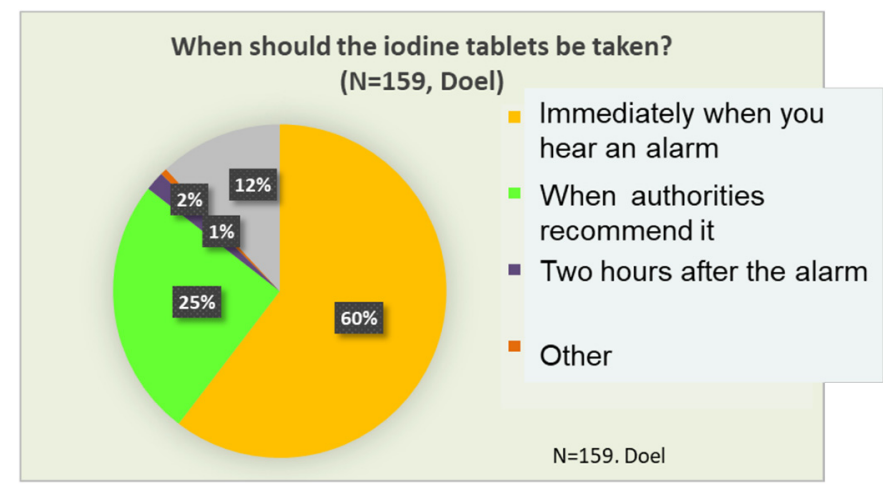

Fig. 30. Example of societal uncertainties regarding the timing of stable iodine intake.

decisions to recover acceptable living conditions. The posters have presented and discussed the objectives, materials and methods, results and conclusions of the stakeholder engagement through scenario-based discussion panels in Belgium, France, Greece, Ireland, The Netherlands, Norway, Portugal, Slovak Republic and Spain.

Based on the cross-country comparison of the findings and conclusions of the national panels the recommendation associated with different category of uncertainties (governance, environment, human health and safety, social, economy and transversal issues) have been presented as it is given in Figure 29 and discussed in the working groups under the category of uncertainty.

Each recommendation has been thoroughly discussed within the working group with the focus on why this recommendation is suggested and the way how it could be fulfilled with the indication of the different stakeholders who can contribute to its fulfilment.

\subsubsection{Key feedback from WP4 discussion on guidelines and recommendations}

The next questions were proposed to participants' groups to facilitate the discussions:

- Do you agree with this recommendation?

- Is there anything missing?

- What should be improved or better explained?

The participants expressed their views and suggestions to improve this first set of recommendations. Working groups' leaders collected these comments, which have been considered to finalize the recommendations presented in more details in Durand et al. (2020).

\subsection{Social, ethical and communicational aspects of uncertainty management (WP5)}

CONFIDENCE work package 5 addressed social uncertainties faced by stakeholders including wider publics. The objectives were to identify societal uncertainties in emergency and post-accident situations, highlight the ethical implications of uncertainty management, investigate citizens'

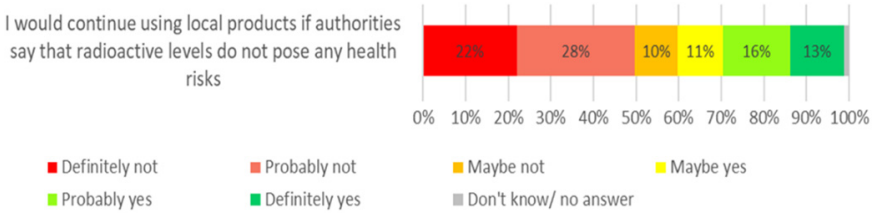

Fig. 31. Example of uncertainties related to food consumption.

and emergency actors' sense-making of uncertainties, and subsequent decisions, develop improved communication of uncertainties and provide advice for improving emergency preparedness, response and recovery. The WP5 scenariobased facilitated discussion focused on two key communication challenges, one in the early phase, the other in the transition phase:

- communicating about the intake of iodine tablets;

- communicating about food safety.

Participants to the dissemination workshop were divided in groups, each group addressing one of these two topics. Participants were also referred to the communication recommendations formulated within CONFIDENCE WP5 (Perko et al., 2020).

For iodine tables, social uncertainties mentioned in the task introduction included lack of knowledge about the correct use (example given in Fig. 30) and the protective role of iodine tablets among the residents living close to nuclear installations, potential non-compliance with official advice, people not having iodine tablets at home, and people not being informed about what to do in case of accident (Turcanu et al., 2020).

The task was formulated as follows:

- Borssele scenario; 21:00, possible release within 12 hours. Population: 300,000 ;

- What are the most important things to communicate?

- How to do that using a text message (SMS*) for people currently located in the potential area for stable iodine intake?

The exercise proved complex but was appreciated by the participants as an opportunity to reflect on social and ethical issues, as well as practical challenges in preparing for stable iodine intake. Groups pointed out that communication would differ according to the existing level of iodine tablet distribution, and that there would be particular challenges with how to distribute the stable iodine tablets in an effective way for those who do not have tablets (e.g. tourists in the area, queues at pharmacies). Potential problems with different intervention levels between Belgium and the Netherlands were noted, and authorities would need to be prepared for reactions on social media and potential rumours. The technical challenges of sending SMS messages (number of characters, how to distribute, who is likely to be excluded) were discussed as well as how the time and day would impact on the message (Sunday evening or Monday morning), draft texts from all groups identified the need to provide links to credible sources.

For the task related to food safety, the social uncertainties introduced at the onset of the task included the potential reluctance to consume products with residual radioactivity, the 

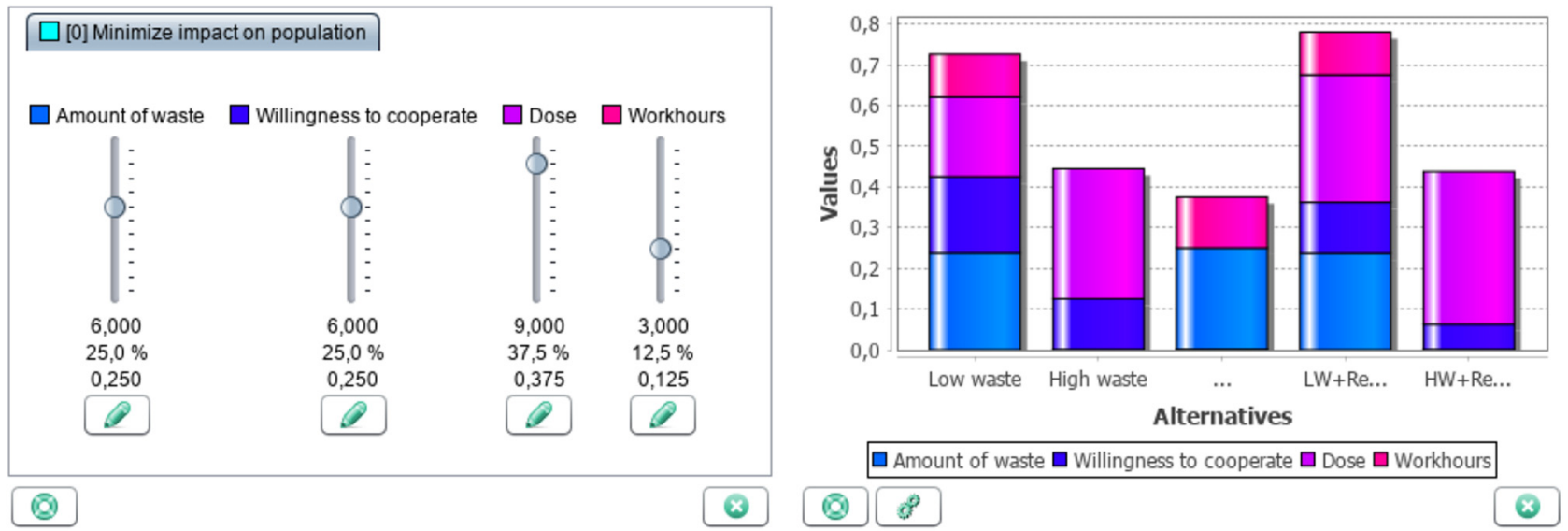

Fig. 32. Weights of criteria and strategies order visualisation.

different interpretations of risk by different actors, the potential for stigmatisation of affected areas, the support needed by local actors (example is given in Fig. 31).

The task for participants working in this group was formulated as follows:

- "All milk from the Zeeland area on the market is below MPL's";

- How would you communicate this to the public to avoid a boycott in the Netherlands and abroad?

- Identify challenges.

- What are the most important messages to convey?

- How would you communicate this?

Participants recognised again the complexity of this task. Explaining that milk containing radioactivity is below MPL's is challenging, particularly since the word "contaminated" has a negative connotation. The exact message would depend on whether some milk in the Zeeland region, or neighbouring regions, were above MPLs, or whether all milk in Zeeland was below MPLs. The question was raised as to what constitutes a "safe" level of radioactivity in milk. Participants agreed that communicating that a product is safe for consumption is essential, but could not agree whether the milk discussed in this scenario is safe or not (i.e., whether or not milk in Zeeland would actually be below MPLs). Information on monitoring strategies would be likely to play an important role in consumer trust as well as who was giving the message. Concerns were also raised regarding breastfeeding for babies.

\subsubsection{Feedback from WP5 scenario-based discussions}

Key feedback from both discussions was that this type of communication is complex and challenging, and that preparation before an incident is essential.

\subsection{Decision making under uncertainties (WP6)}

The task of MCDA scenario-based facilitated discussion focused on the urban decontamination of the municipality Cromstrijen/Numansdorp based on the outputs of WP4 scenario-based discussions using the method of the facilitated scenario-based discussion in combination with the MCDA tool.

Five different countermeasure strategies have been discussed:

- no actions, only monitoring;

- low waste strategy;

- high waste strategy;

- low waste + relocation;

- high waste + relocation.

The strategy developments itself as well as main concerns when facing the recovery strategy, objectives to pursue in the recovery strategy, main factors and key criteria for the strategy selection and main uncertainties affecting the decision about recovery strategy have been discussed by all participants in groups within the previous work of WP4. Each group filled the questionnaire. The results were collected and analysed for the purpose of the MCDA scenario-based facilitated discussion.

The summary of conclusions of the outputs of the WP4 scenario-based discussions has been presented to all participants before the MCDA scenario-based facilitated discussion.

It was agreed, that main concerns are:

- social impacts;

- health impacts;

- feasibility;

- environmental + economical and other issues.

The main objectives of the recovery plan are:

- minimise the impact on the population;

- minimise the radiological impact;

- improve the public confidence.

The discussions have started with following inputs:

- Goal: minimise impact in the population;

- Key criteria/attributes:

- social impacts: community involvement and community acceptance, 


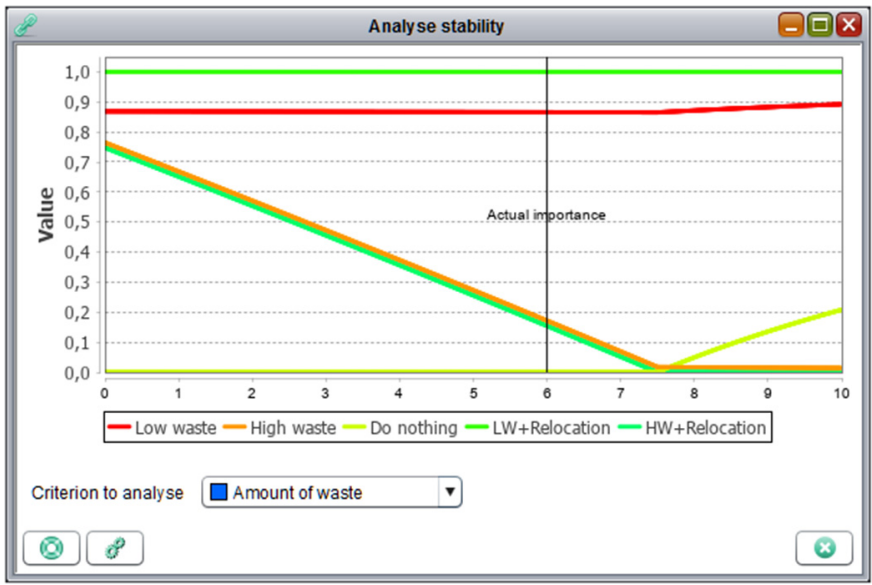

Fig. 33. Stability analysis for weight of criterion "Amount of waste".

- health impacts: psychological consequences and avoidance of doses,

- feasibility: duration and workforce,

- environmental: waste production and waste disposal,

- economic: employment - human capital.

\section{- Uncertainties:}

- What to do with wastes? $\rightarrow$ waste production $\rightarrow$ waste amount - $(\mathrm{H})$

- How to engage the community? $\rightarrow$ community involvement $\rightarrow$ willingness of population to cooperate on strategy implementation - (S),

- duration of the countermeasures implementation $\rightarrow$ dependent on workforce $\rightarrow$ number of workers needed $-(\mathrm{H})$,

- data concerning the number of cancers $\rightarrow$ avoid doses $\rightarrow$ doses - $(\mathrm{H})$,

- roles and decisions: local versus regional and national authorities $\rightarrow$ community involvement $\rightarrow$ Willingness of population to cooperate on strategy implementation - (S).

A selected group of 4 stakeholders who played a role of decision makers have acted as Crisis Centre at a stage and were observed and supported by the remaining participants of the workshop.

Discussion among the remaining participants in small groups was encouraged. The crisis manager with the role "mayor" called in additional advisors to support her in the official discussion, thus forming a second group and providing in one voice their decisions. The discussions were facilitated by experienced independent facilitators. The MCDA tool was overhead presented during the ongoing discussion. The criteria weights and values were displayed during the discussion while the resulting ranking of strategies was initially hidden.

The values for the "hard" $(\mathrm{H})$ criteria such as waste amount, number of workers needed and doses have been taken directly from the JRODOS calculation results. The values for the "soft" (S) criterion as "Willingness of population to cooperate on strategy implementation" were estimated and agreed by the team of decision makers with support from other participants.
The thorough discussion in all groups took place during the estimation and agreement on the weights of the criteria. At that stage of discussion, facilitators helped to interactively observe and evaluate the changes in criteria or weights using the MCDA tool. The different opinions on the weights were investigated in the MCDA tool and then consolidated into one common agreement.

Having agreed on the initial weights for particular criteria they have been assessed to those using the MCDA tool. The resulting order of the strategies was uncovered and displayed to participants after the first iteration using the bar type of visualisation as it is presented in the Figure 32. Each criterion contributed with its weight to the final ranking of recovery strategies.

The stability of current ranking was discussed using the visualisation in the MCDA tool.

An analysis tool of the MCDA provided a chart which graphically displayed what would happen if a specific weight of a criterion was to be changed, respectively if it could not be determined accurately (Fig. 33). Crossing lines indicate a change in ranking, while no crossings within a wide range of the weight indicate stability even against uncertainty. This was understood and valued by the decision makers. From this, they also concluded that ranking positions with close values should not be considered absolute but treated as equally possible.

\subsubsection{Feedback from WP6 scenario-based discussions}

The MCDA tool was evaluated to be very helpful for decision makers as it helps a clear structuring of the important facts influencing the choice of an appropriate strategy. Additionally, it triggered interesting discussions on criteria meanings e.g. what "protect the health of the public" actually meant under these conditions, which helped the groups to better understand each other's motivation. It was definitely recognized by participants that the tool has the supportive character and the results could not be directly taken without deeper understanding and analysis of the actual outcome. Political decisions as one of the factors influencing the decision was pointed out and experienced in the discussion transparently. It was also pointed out whether criteria should be independent from each other or not, as in real life many decision criteria are linked e.g. by costs. Therefore it is very difficult to determine independent criteria for decision making. This stressed even more the need for awareness that the advised best strategy should not be executed blindly but regarded in respect to the determining criteria with their dependencies and uncertainties.

\subsection{Round table discussions}

The round table and panel discussions formed a valuable part of the CONFIDENCE dissemination workshop and focused on:

- achievements and way forward based on the research results and outputs of each CONFIDENCE work package;

- feedback from end users, represented by participants from IAEA, SURO (Czech Republic), PHE (UK), STUK (Finland) and APA (Portugal), on outputs and remaining research requirements or improvements in models/guidance; 
- Strategic Research Agendas and CONCERT Joint Road Map in view ofCONFIDENCE results presented by members of the NERIS, ALLIANCE, EURADOS and SHARE research platforms and the CONCERT EJP coordinator;

- further development and conclusions presented by CONFIDENCE project coordinator, IAEA and ICRP (Committee 4) representatives and the CONCERT EJP coordinator.

The key feedback is discussed in Raskob et al. (2020).

\section{Conclusions}

The CONFIDENCE dissemination workshop was interactive and dynamic. It provided a floor for education activities in a form of presentations and poster sessions, training using the scenario-based activities and table-top exercises in a form of scenario-based facilitated discussions. The wide dissemination of results was done in an understandable way connected directly to demonstration and practical use. Thorough presentations were backed up by posters with more details and a poster session giving possibilities for attendees to discuss the poster/CONFIDENCE with the authors. Scenario-based facilitated discussions provided the opportunity for round table group working so that all participants were actively involved and expressed their views, experiences, were able to raise questions and receive answers. Round table discussions as well as panel discussions enable feedback from participants. The sharing of knowledge and experiences among generations of scientists, researchers and experts took place in a very open and effective way creating connections for future research and development in the area of modelling and decision making in nuclear emergencies.

Acknowledgement. The work described in this paper was conducted within the CONFIDENCE project, which was part of the CONCERT project. This project has received funding from the Euratom research and training programme 20142018 under grant agreement No. 662287.

Disclaimer (Art. 29.5 GA). This publication reflects only the author's view. Responsibility for the information and views expressed therein lies entirely with the authors. The European Commission is not responsible for any use that may be made of the information it contains.

\section{References}

Beresford NA, Barnett CL, Chaplow J, Lofts S, Wells C, Brown JE, Hosseini A, Thørring H, Almahayni T, Sweeck L, Guillén J, Lind O-C, Oughton DH, Salbu B, Teien H-C, Perez-Sánchez D, Real A. 2020. CONFIDENCE overview of improvements in radioecological human food chain models and future needs. Radioprotection 55(HS1). https://doi.org/10.1051/radiopro/2020019.

Brown JE, Avila R, Barnett CL, Beresford NA, Hosseini A, Lind O-C, Oughton DH, Perez D, Salbu B, Teien HC, Thørring H. 2019. Improving models and learning from post-Fukushima studies. CONCERT deliverable D9.13. Available from: https://www. concert-h2020.eu/en/Publications.

Brown JE, Beresford NA, Hosseini A, Barnett CL. 2020. Applying process-based models to the Borssele scenario. Radioprotection 55(HS1). https://doi.org/10.1051/radiopro/2020020.
Charnock T, Andersson K, Trueba C, Montero M. 2020. Uncertainties confronting stakeholders and decision-makers in planning intervention in urban and agricultural scenarios. Radioprotection 55(HS1). https://doi.org/10.1051/radiopro/2020021.

Durand V, Maître M, Croüail P, Schneider T, Sala R, Marques-Nunes P, Paiva I, Monteiro Gil O, Reis M, Hilliard C, Tafili V, Twenhöfel C, van Asselt E, Trueba C, Montero M, Duranova T. 2020. Towards an improved decision-making process to better cope with uncertainties following a nuclear accident. Radioprotection 55 (HS1). https://doi.org/10.1051/radiopro/2020023.

Duranova T, Beresford NA, Perko T, Raskob W. 2020. Education and training activities in the Euratom CONFIDENCE project. Radioprotection 55(HS1). https://doi.org/10.1051/radiopro/ 2020011.

Geertsema G, de Vries H, Sheele R. 2019. High resolution meteorological ensemble data for CONFIDENCE research on uncertainties in atmospheric dispersion in the (pre-)release phase of a nuclear accident. In: 19th International Conference on Harmonisation within Atmospheric Dispersion Modelling for Regulatory Purposes, 3-6 June, Bruges, Belgium.

Hamburger T, Gering F, Ievdin I, Schantz S, Geertsema G, de Vries H. 2020. Uncertainty propagation from ensemble dispersion simulations through a terrestrial food chain and dose model. Radioprotection 55(HS1). https://doi.org/10.1051/radiopro/ 2020014.

Korsakissok I, Périllat R, Andronopoulos S, Bedwell P, Berge E, Charnock T, Geertsema G, Gering F, Hamburger T, Klein H, Leadbetter S, Lind OC, Pázmándi T, Rudas C, Salbu B, Sogachev A, Syed N, Tomas J, Ulimoen M, de Vries H, Wellings J. 2020. Uncertainty propagation in atmospheric dispersion models for radiological emergencies in the pre- and early release phase: summary of case studies. Radioprotection 55(HS1). https://doi. org/10.1051/radiopro/2020013.

Montero M, Sala R, Trueba C, García-Puerta B, Abelshausen B, Bohunova J, Croüail P, Durand V, Duranova T, Hilliard C, Maître M, Mitrakos M, Monteiro Gil O, Nunes P, Paiva I, Reis M, Schneider T, Skuterud L, Smith V, Tafili V, Thørring H, Turcanu C, Twenhöfel C, van Asselt E. 2020. Stakeholder involvement through national panels and surveys to address the issues and uncertainties arising in the preparedness and management of the transition phase. Radioprotection 55(HS1). https://doi.org/ 10.1051/radiopro/2020022.

Nisbet AF, Brown J, Howard BJ, Beresford NA, Ollagnon H, Turcanu C, Camps J, Andersson K, Rantavaara A, Ikäheimonen T, Duranova T, Oughton D, Kirchner G, Papachristodoulou C, Ioannides K, Kwakman P. 2010. Decision aiding handbooks for managing contaminated food production systems, drinking water and inhabited areas in Europe. Radioprotection 45(5 Suppl.): S23-S37.

Perko T, Benighaus L, Tomkiv Y, Wolf HV. 2020. Guidance on communicating about uncertainties in nuclear emergency management. Radioprotection 55(HS1). https://doi.org/10.1051/radio pro/2020028.

Raskob W, Trybushnyi D, Ievdin I, Zheleznyak M. 2011. JRODOS: platform for improved long-term countermeasures modelling and management. Radioprotection 46(6): S731-S736. https://doi.org/ 10.1051/radiopro/20116865s

Raskob W, Beresford NA, Duranova T, Korsakissok I, Mathieu A, Montero M, Müller T, Turcanu C, Woda C. 2020. CONFIDENCE: achievements and way forward. Radioprotection 55(HS1). https:// doi.org/10.1051/radiopro/2020010.

Turcanu C, Perko T, Sala R, Wolf HV, Camps J, Oughton D. 2020. Social uncertainties related to stable iodine intake in a nuclear 
emergency. Radioprotection 55(HS1). https://doi.org/10.1051/ radiopro/2020027.

van Asselt E, Twenhöfel C, Smetsers R. 2019. Stakeholder engagement through scenario-based discussion panels. Part B05. Report of the Dutch National Panel. CONCERT deliverable D9.22. Available from: https://www.concert-h2020.eu/en/Publica tions.

Walsh L, Ulanowski A, Kaiser JC, Woda C, Raskob W. 2019. Risk bases can complement dose bases for implementing and optimizing a radiological protection strategy in urgent and transition emergency phases. Radiat. Environ. Biophys. 58: 539-552.

Walsh L, Ulanowski A, Kaiser JC, Woda C, Raskob W. 2020. A new European cancer risk assessment tool for application after nuclear accidents. Radioprotection 55(HS1). https://doi.org/10.1051/ radiopro/2020018.

Woda C, Walsh L, Kaiser JC, Ulanowski A, Hamburger T, Gering F, Duranova T, Raskob W. In preparation. Cancer risk assessment for supporting decision making in the early phase of a nuclear accident - results of the scenario-based workshop of CONFIDENCE.

Cite this article as: Duranova T, Bedwell P, Beresford NA, Bleher M, Gering F, Geertsema G, Hamburger T, Kaiser JC, Korsakissok I, Leadbetter SJ, Montero M, Müller T, Oughton D, Perko T, Raskob W, Tomas J, Turcanu C, de Vries H, Walsh L, Woda C. 2020. CONFIDENCE dissemination meeting: Summary on the scenario-based workshop. Radioprotection 55(HS1): S17-S37 